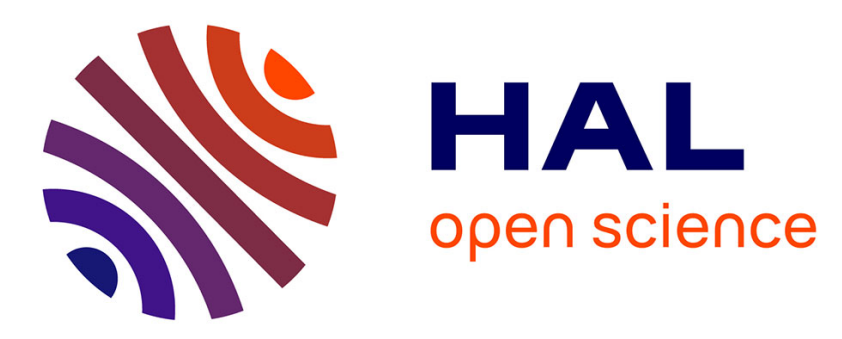

\title{
An approach of using primitive feature analysis in manufacturability analysis systems for micro-milling/drilling
}

\author{
Syaimak Abdul Shukor, Dragos Axinte
}

\section{To cite this version:}

Syaimak Abdul Shukor, Dragos Axinte. An approach of using primitive feature analysis in manufacturability analysis systems for micro-milling/drilling. International Journal of Computer Integrated Manufacturing, 2009, 22 (08), pp.727-744. 10.1080/09511920802632176 . hal-00513413

\section{HAL Id: hal-00513413 \\ https://hal.science/hal-00513413}

Submitted on 1 Sep 2010

HAL is a multi-disciplinary open access archive for the deposit and dissemination of scientific research documents, whether they are published or not. The documents may come from teaching and research institutions in France or abroad, or from public or private research centers.
L'archive ouverte pluridisciplinaire HAL, est destinée au dépôt et à la diffusion de documents scientifiques de niveau recherche, publiés ou non, émanant des établissements d'enseignement et de recherche français ou étrangers, des laboratoires publics ou privés. 


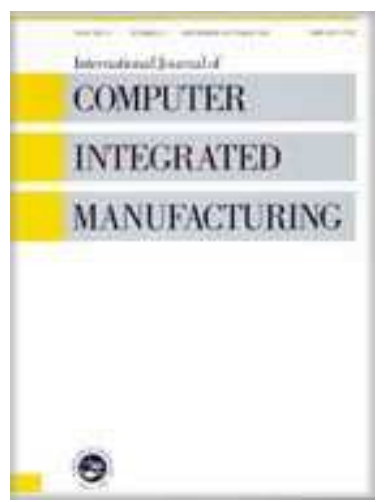

\section{An approach of using primitive feature analysis in manufacturability analysis systems for micro- milling/drilling}

\begin{tabular}{|r|l|}
\hline Journal: & International Journal of Computer Integrated Manufacturing \\
\hline Manuscript ID: & TCIM-2008-IJCIM-0025.R1 \\
\hline Manuscript Type: & Original Manuscript \\
\hline Date Submitted by the & 20 -Oct-2008 \\
\hline Author: & $\begin{array}{r}\text { Abdul Shukor, Syaimak; University of Nottingham, School of } \\
\text { Mechanical, Materials and Manufacturing Engineering } \\
\text { Materials and Manufacturing Engineering }\end{array}$ \\
\hline Keywords: & $\begin{array}{l}\text { MANUFACTURING INFORMATION SYSTEMS, CIM, DATA } \\
\text { ENVELOPMENT ANALYSIS, EXPERT SYSTEMS, FEATURE } \\
\text { EXTRACTION, MACHINABILITY }\end{array}$ \\
\hline Keywords (user): & Manufacturability Analysis System, Primitive Feature Analysis \\
\hline
\end{tabular}

\section{S) ScholaroNE \\ Manuscript Central}




\title{
An approach of using Primitive Feature Analysis in Manufacturability Analysis Systems for micro-milling/drilling
}

\author{
A.S. SYAIMAK and *D.A.AXINTE
}

School of Mechanical, Materials and Manufacturing Engineering, University of Nottingham

*Dragos Axinte, PhD, CEng, FIMechE (Corresponding author)

Associate Professor

University of Nottingham,

School of Mechanical, Materials and Manufacturing Engineering, Coates Building,

Nottingham, NG7 2RD

United Kingdom

Tel: $+44(0) 1159514117$

Fax: +44 (0)1159513800

Email: Dragos.Axinte@nottingham.ac.uk 
An approach of using primitive feature analysis in manufacturability analysis systems for micro-milling/drilling

\author{
S. A. Shukor and D. A. Axinte* \\ School of Mechanical, Materials and Manufacturing Engineering, University of Nottingham, United Kingdom
}

Manufacturability Analysis Systems (MASs) have been developed to enable the evaluation of easy of manufacture parts during the design stage enabling the reduction of costs and time to market of the designed products. The feature analysis approach is one of the methods used to gather information from the proposed design for manufacturability assessment purposes. The objective of this paper is to explore a new technique which is Primitive Features Analysis (PFA) in assessing the manufacturability of proposed designs and to demonstrate further its implementation in developed MAS explicitly for a custom-built miniature 4-axis machine tool (MMT). In the introduction to this paper, the definition, methodology and importance of MAS are discussed along with their relations to feature analysis. PFA analyses the defined primitive features (e.g. box, sphere, cylinder, cone, prism) of the proposed design based on their positions, interactions and geometrical details. The analysis is supported by a database containing rules and constraints that are specific to micro-machining processes in MMT; these account for primitive features orientations/interactions as well as machining conditions and workpiece materials. First, an index is evaluated for each primitive feature to reflect its manufacturability while taking into account key quality output measures (e.g. tolerance, surface roughness). Then, the overall manufacturability index is calculated taking into consideration the possible interactions/constraints among neighbouring primitive features of the desired component. The PFA technique was implemented within a unique algorithm consisting of data input mechanism, Initial Assessment (IA), Single Feature Analysis (SFA) and Coupled Feature Analysis (CFA) by use of Visual Basic.NET®. The new MAS is able to illustrate the analysis of the PFA technique and it provides outputs such as redesign suggestions and manufacturability indices. Finally, the paper discusses on the advantages, possible limitations of this approach followed by suggestions for future developments.

Keywords: primitive feature analysis; manufacturability analysis system; manufacturability index; single feature analysis; coupled feature analysis

\title{
1. Introduction
}

Manufacturability Analysis Systems (MASs) have been developed to ensure that the "ready for manufacture" designs are exempted from repetitive iterations occurring at the interface between design and manufacturing activities when the sequential approach of the product development life cycle is taken into account. MASs have been implemented to allow manufacturability aspects to be analysed during the design stage and to enable further a "smooth" transition between the design and manufacturing stages (Gupta 1997). Manufacturability is defined as the ability to reproduce a given part with minimal waste, such that it satisfies the requirements in intended use while meeting the business goal (Rao 1994). The idea of analysing the manufacturability aspects at the design stage is a part of materialising the Design for Manufacture (DFM) concept which supports the Concurrent Engineering (CE) philosophy aiming to reduce the time from design to manufacture (Pham 1998).

*Corresponding author. Email: dragos.axinte@ nottingham.ac.uk 
With the advances of current CAD/CAM systems and the introduction of CE philosophy in product development, robust MASs are needed to fill technological/communication gaps between design and manufacturing stages of the products. It is envisaged that MASs could enable the analysis of both manufacturability and functionality aspects such as dimensions/tolerances, surface finish, machining strategies related to material properties and part geometrical specifications; all considered at the early stages of product development with direct implications on the reduction of lead times of the product to the market (Boothroyd 1994; Rao 1999; Shukor 2007). The assessment of manufacturability aspects of the proposed designs not only acts as a support tool to generate designs with the correct measures but could also provide redesign suggestions, material and process selections, process sequencing and set-up of process planning.

Examples of MAS implementation can cover a wide range of applications: from shipbuilding projects, where MAS supports automated virtual assembly of parts/sub-assemblies (Sasaki 2003), designing an improved version of golf club heads (Chen 2001), assist product designers, process planners and die designers working in small and medium sheet metalworking industries for assessing manufacturability of presswork parts (Kumar 2006) and selecting suitable material (powder for packing and compaction) in powder metallurgy process for mould fabrication (Smith 1999; Cherian 2001). Within the broader context of modern design and manufacturing digitisation, the steps made towards the unification of concepts into intelligent and industrially usable MAS is regarded as a strategic step towards next fully integrated production systems.

As product development technology becomes more advanced, the size of devices produced decreases and this is where microproducts came into view. Micro-engineering deals with the development and manufacture of products, whose functional features or at least one dimension are at micrometric level (Alting 2003). Micro-products such as sensors, lenses, optical, surgery devices, gears, and actuators have become demanded products in industry such as IT, Medical and Biomedical, Automotive, Telecommunication and Electronic Industries. The use of micro-products and micro-components has been strongly increased through the past 5 years and the product development and design on new micro-products will be the core competence of the companies in future (Alting 2003). The increasing demands of micro-products in various industries have geared up the development of specific micro-manufacturing processes and technologies. Thus, all the constitutive elements of micro-fabrication systems have to be optimised to enable cost and time efficient mass generation of ever-growing micro engineered products. The needs to bring micro-products faster to the market caused the development and the design phases to become more challenging tasks. Methods used to design the products with the required quality specifications and can be fabricated easily is one of the main issue in designing micro-products.

Even though micro-machining (e.g. micro-milling/drilling/turning) is becoming more popular for generating small and high accuracy parts (Masuzawa 2000; Alting 2003; Dimov 2004) there is no clear indication that systems to assist with manufacturability assessment of these part are scarce. MASs have been applied to various manufacturing processes it can be noted that such systems mainly addressed macromanufacturing processes such as cutting or forming, while less attention was paid to micro-manufacturing processes (Shukor 2007). Due to increase demands of micro-products in the current market, the applicability of MAS in this field has a big research potential that needs to be explored as it assists in fabricating a high quality micro-products. In order to design competitive micro-products, which ideally fulfil the required product functions, the designers need to develop products that relate to the fast-developing manufacturing details and rules (Alberz 2004). Thus, a systematic approach in designing quality micro-products allows the designs to be easily manufactured and compatible with the production needs. This means that the designer is able to check the micro-manufacturability aspects in their designs before submitting them for fabrication. MASs has been proved to work for macro-manufacturing processes (Smith 1999; Chen 2001; Cherian 2001; 
Sasaki 2003; Kumar 2006). An implication of this is the possibility of the MAS to check micromanufacturability aspects such as materials used, manufacturing processes involved, acceptable and suitable tolerances and dimensions of micro-products. Therefore, there is and will be definite need for analysing the micro-manufacturability aspects during the design stage products in order to produce accurate and costeffective micro-products.

MASs have been developed using different combination of approaches, technologies, software and tools. Most MASs have been constructed based on a three-step, unidirectional flowchart methodology that includes data input mechanisms, inference engines for manufacturability analysis and output reporting. Figure 1 shows the flowchart of such methodologies for developing MASs. The first is the development of the input mechanism where all required design data and manufacturing information are fed into the system. The next step is to analyse the gathered input for performing part manufacturability assessment; here data are analysed according to the manufacturability constraints and rules to determine the difficulty level for manufacture of the proposed design. The final component in MASs' methodology consists of generating the output to reflect the evaluation of manufacturability aspects of the proposed designs while interactively assisting the operators in (re)considering manufacturing aspects at the design stage.

Figure 1. Basic methodology of MAS development

Recent reports on current MASs (Shukor 2007) comment on three mechanisms to input data into the system that can be performed as follows: i) direct data extraction from CAD models; ii) through user-system interactions; iii) collection of manufacturing information. The type of data extracted/collected from "to be analysed" part consists of dimensional/geometrical details, machinability/mechanical properties of the workpiece material, material removal/production rates and quality control measures such as tolerances and surface finish.

There are several techniques that have been implemented to obtain data directly from CAD model such as: feature-based extraction system (Kamrani 1996; Gupta 1997; Brissaud 2000; Jacquel 2000; Jia 2004; Korosec 2005); neutral files usage (Yuyin 1996; Ramana 2006; Tomovic 2006); embedded algorithm into CAD system (Lee 1997); 3D recognition model based on the design specifications on the CAD model (Chen 2001). Even though, most of the developed MASs used feature-extraction system to obtain related data from CAD model but it has some problems. One major drawback of this approach is complexity of embedding such data extraction systems into highly flexible formats that allow feeding the "necessary and sufficient" data into customised MASs. Besides that, this technique suffers limitations such as imprecision/fuzziness of extracted data, inflexibility of data type and difficulty in interpreting the relationships between various features of the part. As known, the development of feature-extraction systems is still a stringent on-going research topic targeted to identify ways to collect accurate and self-sufficient data/design details from the features.

While, the other two mechanisms are still not yet widely used in MAS development and should be explored further. In user-system interaction technique (Venkatachalam 1993; Zha 2003; Kumar 2006); the system prompts the user with questions leading towards collection of necessary design information. As example, during a consultation session, users input the needed data in the provided interface that once being sufficient, the programs starts to analyse them based on the rules embedded in KB (Kumar 2006). In this system, important data and information related to fabricating a sheet metal component such as type of material, sheet thickness, minimum corner radius sheet metal part, minimum width of slots along blank profile, shapes and dimensions of holes on the part and maximum dimension (length/width) of component are 
being gathered from user-system interaction mechanism for the purpose of manufacturability assessment (Kumar 2006).

Regarding the third mechanism, all information related to manufacturing process, workpiece materials and tooling are available for user to select at the data input stage (Ravinwongse 1997; Giachetti 2005). Here, users are allowed to choose related data and parameters from the collection of manufacturing information embedded in the system. The difference clearly owned by this mechanism compared to the previous one is all information are readily embedded, and users only have to choose them appropriately, while in the previous mechanism, users are required to input all needed data through the interface during the interaction.

Instead of using laborious methods of data extraction from CAD models, this paper introduces a technique that combines two mechanisms (user-system interaction and collection of manufacturing information) in collecting data from a CAD model. It proposes a new structure for MASs that relies on a "translation" of CAD essential information into a set of algebraic primitive features whose manufacturability are analysed in a singular and interrelated (i.e. coupled) manner. In contrast with the common approach that focuses on extracting the data based on a wide range of single entity features (e.g. holes, slots, pockets, steps, dovetails, counter bores/sinks), the paper studies the opportunity of feature analysis based on a reduced number of algebraic primitives (e.g. box, sphere, cylinder, prisms, cones). The introduction of Primitive Feature Analysis (PFA) technique manifests a new opportunity in collecting information from CAD model and further to analyse their manufacturability as a prerequisite for more efficient MASs. In CAD systems, the Primitive Feature (PF) is a known concept; by using this as the foundation for the feature analysis in PFA technique, it is believed, MAS user will define the part easier.

The overall aim of the research is to develop a MAS dedicated for a custom-built miniature 4-axis machine tool (MMT) where the PFA technique is implemented in the data input mechanism and used throughout the entire MAS. The approach of PFA is to define and collect important data from the proposed CAD model, based on the contained PF, and further to express their existence as bosses (positive PF) or pockets (negative PF) on the analysed parts. Furthermore, once the manufacturability of each negative/positive PF is evaluated, the next step is to interact them by assessing their degrees of compatibilities that lead to the evaluation of part manufacturability by use of aggregate indices. Figure 1 shows where the PFA technique is implemented in MAS development.

In this new approach, PFA was introduced to be implemented between the data input and manufacturability assessment module. Besides combining the two input mechanisms together, it also integrates the data input and manufacturability assessment phase in one step in the system. Data that are collected can be analysed directly and feedbacks are given promptly to user.

\subsection{Scope of the paper}

The purpose of this paper is to explore the opportunity of using the PFA technique, as part of integrated MAS, to develop the inference engine that assesses the manufacturability of micro-parts generated through a MMT that can operates micro-milling/drilling. This paper discussed the following issues:

- The PFA technique is implemented in MAS for obtaining information about the proposed design for its manufacturability assessment. The PFA technique relies on algebraic (boss - positive; cavity - 
negative) primitive features such as box, sphere, cylinder, prisms and cones contained in the proposed CAD model and the interactions among them.

- The PFA technique algorithm consists of three elements: Single Feature Analysis (SFA), Coupled Feature Analysis (CFA) and Output Mechanism; the concepts, objectives and flowcharts of each element are discussed. Then, the implementation of the PFA on an example of a CAD model is described and demonstrated. Additionally, the execution of the PFA strategy in unitary MAS is defined and simulated.

○ Furthermore, details on how PFA technique was implemented using Visual Basic.NET® (VB) into the new MAS is presented. Rule-Based Systems (RBS) supported by database containing manufacturing information on micro-milling/drilling was used as a basis for constructing the inference engine of the MAS.

\section{Primitive feature analysis (PFA) technique}

\subsection{Introduction of PFA}

Primitive Feature Analysis (PFA) is defined as a method for assessing the manufacturability of singular Primitive Feature (PF) as well as their interactions (coupled PFs) in making possible the realisation of the CAD model and further enabling the manufacturability analysis of the part. In this approach the PFs are: box, sphere, cylinder, cone and prism (Table 1). During the user-system interaction session, the user has to recognize all the PFs contained in the proposed design and to identify their geometrical characteristics. If there are features that cannot be considered, in a simplified way, as PFs, the user will "decompose" them to fit the requirements of the system. Table 1 presents the essential geometrical data required from each PF to assist the analysis process. The PFA technique is based on the position, interaction and geometrical details of all PFs identified in the proposed design. The data collected during the user-system interaction are then used for the manufacturability analysis based on the mechanisms discussed in the following part.

Table 1. Illustration of Primitive Features

The manufacturability analysis which is based on the PFA technique has been expressed through specific Manufacturability Indices (MIs). MIs reflect the relative ease of machining of the component based on associated ratings of various aspects such as PF characteristics, surface roughness, tool dimension, tolerances and machinability of selected materials. MI evaluation is based on the results from Single Feature Analysis (SFA) performed for each PF that is followed by Coupled Feature Analysis (CFA) to reflect their interactions. In calculating the MI at SFA level, there are four key characteristics that have been considered: form of singular PF (as in Table 1), surface roughness, tolerances and tool diameter effect on machining the PF's minimum curvature. For each key characteristic an MI value is assigned.

MI for singular PF $\left(\mathrm{MI}_{\mathrm{PF}}\right)$ reflects the level of manufacturability based on the geometrical aspects of a $\mathrm{PF}$ such as: orientation of the PF (boss or cavity), shape (straight, negative or positive tapered) and end-corner specifications. MI for surface roughness $\left(\mathrm{MI}_{\mathrm{Ra}}\right)$, tolerances $\left(\mathrm{MI}_{\mathrm{TOL}}\right)$ and tool dimension effect $\left(\mathrm{MI}_{\mathrm{DIM}}\right)$ emulate the quality measures of the part as chosen by the user. All these indices are summed up to an index $\left(\mathrm{MI}_{\mathrm{SFA}}\right)$ that reflects the level of manufacturability for the analysed PF as shown in Equation 1. A weight factor $\left(0<\mathrm{K}_{\mathrm{i}}<1\right)$ is assigned to each index based on the user decision in determining which key characteristics are more important when considering the manufacturability of the PF. 
$M I_{S F A}=\frac{\sum K_{i} \cdot M I_{i}}{4}$, where $i=$ PF, Ra, TOL, DIM

The indices are represented by a rating convention generated based on the MMT specifications, recommended cutting parameters, previous manufacturability evaluations (Ong 1996; Ravinwongse 1997; Ong 2000; Gebresenbet 2002; Ong 2003) and feature analysis (Nasr 2007). The following rating convention for any output measure (e.g. $\mathrm{MI}_{\mathrm{PF}}, \mathrm{MI}_{\mathrm{Ra}}, \mathrm{MI}_{\mathrm{TOL}}, \mathrm{MI}_{\mathrm{SFA}}, \mathrm{MI}_{\mathrm{DIM}}$ ) has been implemented throughout the entire PFA technique (single and coupled features as well as overall analysed part):

- Medium level of manufacturability; for $0.5<\mathrm{MI} \leq \mathbf{1 . 0}$

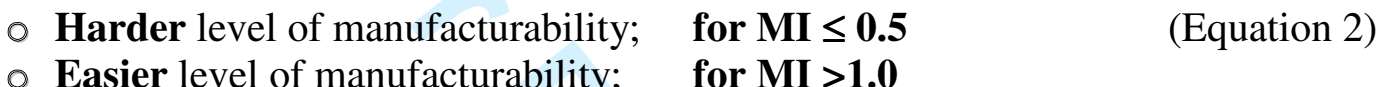

The calculations of indices for all the output measures are described in the next paragraphs.

\subsection{Description of Primitive Feature Analysis (PFA) mechanism}

Figure 2 shows the flowchart with additional graphical representations of analysis done at each phase of the PFA technique: Phase 1 - PF identification; Phase 2 - Single Feature Analysis (SFA); Phase 3 - Coupled Feature Analysis (CFA). The objective of SFA is to assess the level of manufacturability for each defined PF based on its orientation, shape and end-corner specification while the aim of CFA is to analyse the relationships between the PFs based on their relative distances and type of interaction (e.g. attached PF). The results from the SFA determine the $\mathrm{MI}_{\mathrm{SFA}}$ for each identified PF and while the results from CFA conclude the $\mathrm{MI}_{\mathrm{CFA}}$ and $\mathrm{MI}_{\mathrm{OVERALL}}$ for the part.

Figure 2. Flowchart and illustration of PFA technique

As shown in Figure 2, the mechanism of PFA technique is based on the following phases.

Phase 1: PF Identification

i. PF type identification. Each of the PF contained in the proposed CAD model is identified by the user, based on the type of feature shown in Table 1.

ii. Number of PF. A number is assigned to each PF and acts as the unique reference for future analysis in the PFA process.

Phase 2: Single Feature Analysis (SFA)

At the base for the evaluation of $\mathrm{MI}_{\mathrm{SFA}}$ are key elements of SFA that stem from analysis of PF as follows (Figure 3):

i) assign the orientation for each type of PF; ii) assign the shape of PF; iii) specify the type of end-corner; iv) analyse tolerance, dimension and surface roughness; v) evaluate the stiffness ratio $\left(\mathrm{R}_{\mathrm{St}}\right)$ of related PFs.

Figure 3. Single Feature Analysis terminology 
Referring on flowcharts and illustrations in Figure 2 and 3, the SFA approach for identifying and analysing PFs can be described as follows:

i. Type of PF orientation. For each PF, the orientation is assigned whether it is a boss or a cavity as described in Figure 3(a). A boss is a feature that is generated by removing the material outside of it while a cavity is generated by removing the material inside of it. If the feature is assigned as a cavity, its type is determined based on whether it is a blind or through cavity as illustrated in Figure 3(b).

ii. Shape of PF. This is determined based on the side angle value provided by the user during the usersystem interaction session. The category assigned to each PF is whether a positive-tapered, negativetapered or straight shape. Figure 3 (c) illustrates the side angle $(\theta)$ of the PF. A positive-tapered is defined when $\theta>90^{\circ}$ while when $\theta<90^{\circ}$ is considered as negative-tapered and a straight shape when $\theta$ $=90^{\circ}$.

iii. End-corner specification. It is based on the type of end-corner's shape which is classified as sharp, radiused or fillet corner as shown in Figure 3(d).

iv. Analyse quality measures of PF. To enable the evaluation of $\mathrm{MI}_{\mathrm{SFA}}$ the tolerances, surface roughness of the PF and the tooling dimensions have to be specified by the user. These values are associated with ratings indices as specified in Equation 2; the way that each index is calculated for each of these output measures will be discussed in the following paragraphs.

v. Evaluate the stiffness ratio $\left(\mathrm{R}_{\mathrm{St}}\right)$ of PF. The objective of this stage is to evaluate the stiffness of a particular PF by comparing the calculated ratio with pre-set values. Figure 3(e) shows an example of $R_{S t}$ for a box and a cylinder. For a box, the ratio is calculated based on the biggest value either its length or width.

Finally, after these selections/specifications, $\mathrm{MI}_{\mathrm{SFA}}$ values are calculated for each PF (Equation 1) and their ratings expressing the difficulty to manufacture evaluated based on the convention specified in Equation 2. Examples of calculation of $\mathrm{MI}_{\mathrm{SFA}}$ values are presented in the following paragraph (i.e. Example of PFA implementation).

\section{Phase 3: Coupled Feature Analysis (CFA)}

The determined $\mathrm{MI}_{\mathrm{SFA}}$ is taken at the upper level of analysis, i.e. evaluation of $\mathrm{MI}_{\mathrm{CFA}}$. The CFA aims to determine the level of relationship among PFs taking into consideration the relative distance (RD) and the type of interactions between them. Moreover, acceptable relative distances (ARD) used in determining the level of relationship between PFs are pre-defined based on the MMT (e.g. accuracy), cutting tool (e.g. diameters, run-outs) specifications, machinability of workpiece material and cutting parameters (e.g. depth of cuts, cutting speeds, feed rates). The types of interactions between PFs are illustrated in Figure 4.

i. Attached PFs

PFs that are joint or manufacture related when their relative distance (if any) might affect the machining operations and tool path/processing strategies. Figure 4a shows an example of attached PF between a cylinder (PF_A) and a box (PF_B) where both share the same surface. 


\section{ii. Adjacent PFs}

PFs that are not joined but positioned next to each other with the relative distance between them are within the range of ARD. Figure 4(b) shows the example of adjacent PF among three "negative" boxes which are PF_A, PF_B and PF_C.

iii. Independent PFs

PFs that are not joined and the relative distance between them is greater than the ARD range value. Figure 4(c) shows an example of independent PFs: "positive" box (PF_A) and "positive" cylinder (PF_B).

Figure 4. Types of PFs interactions

The calculation of $\mathrm{MI}_{\mathrm{CFA}}$ is subjected to the specifications shown in Table 2; this is done by multiplying $\mathrm{MI}_{\mathrm{SFA}}$ with pre-defined coefficients $\left(\mathrm{K}_{\mathrm{RD}}\right)$ that depend on the comparison between $\mathrm{RD}$ and $\mathrm{ARD}$ as well as the type of feature interactions.

Table 2. Specification of $\mathrm{K}_{\mathrm{RD}}$ for calculating CFA index $\left(\mathrm{MI}_{\mathrm{CFA}}\right)$

Finally, the overall part manufacturability index, $\mathrm{MI}_{\mathrm{OVERALL}}$, is evaluated. This is done taking into consideration $\mathrm{MI}_{\mathrm{CFA}}$ and the machinability index of the workpiece material $\left(\mathrm{MI}_{\mathrm{MAT}}\right)$ as referred to in the literature (Bralla 1986; Anon 2006). Therefore, MI OvERALl of the proposed design is calculated as shown in the Equation 3.

$$
M I_{\text {OVERALL }}=\frac{M I_{M A T}+\sum_{n=1}^{n+1} M I_{C F A}}{n} \text {, where } n=\text { number of PFs }
$$

\subsection{Example of PFA implementation}

In order to simulate the PFA mechanism discussed above, Figure 5 shows a design of a generic miniature component that comprises singular and coupled features such as through/blind cavities (holes), slots and bosses. This CAD model is analysed based on the PFA mechanism and its results are shown in Tables 3, 4, 5 and 6. Figure 5 also presents the identified PFs which are alphabetically labelled $(\mathrm{A}-\mathrm{H})$.

Figure 5. Views of the proposed CAD design

Referring to the phases in the flowchart (Figure 2), the above proposed design is analysed based on SFA and the summarised results are listed in Table 3. $\mathrm{MI}_{\mathrm{PF}}$ for each PF is based on the combination of result from each element discussed in the SFA phases: type, orientation and shape of PFs as well as end-corner specifications.

Table 3. Results from Single Feature Analysis

The determination of $\mathrm{MI}_{\mathrm{PF}}$ started with the exploration of results as illustrated in Table 3 (refer to the arrows). All results of SFA elements are combined and analysed based on pre-defined IF-THEN clauses dependent on machining experiences, MMT specifications, geometrical effects, part quality measures, feature analysis, usual practice of fabrication of specific features, material and process constraints and handbooks. 
Each PF has its set of SFA elements' combinations which determines the $\mathrm{MI}_{\mathrm{PF}}$ values based on the predefined conditions. Table 4 presents some of these conditions when a box is considered as primitive feature.

Table 4. An example of PF analysis: A box condition

As example, for PF_A, the combination result is as follow: PF type - "Box"; PF orientation - "Boss"; PF shape - "Straight"; End-corner specifications -"Radiused". This combination leads to an index of 1.5 for MIPF which means that PF_A is easy to manufacture. As for PF_F, the outcome of MI $\mathrm{IF}_{\mathrm{PF}}$ is 1.0 which defines that the level of manufacturing as medium. This resulted from the combination of each element in SFA which are: PF type - "Cylinder"; PF orientation - "Cavity"; PF cavity type- "Blind hole"; PF shape -"Straight" and Endcorner specifications - "None".

The other manufacturability indices $\left(\mathrm{MI}_{\mathrm{DIM}}, \mathrm{MI}_{\mathrm{TOL}}, \mathrm{MI}_{\mathrm{Ra}}\right)$ that are taken into consideration in determining $\mathrm{MI}_{\mathrm{SFA}}$ (Equation 1) are describes as follows:

1. Dimension Index (MI $\left.\mathrm{DIM}_{\mathrm{M}}\right)$

$\mathrm{MI}_{\mathrm{DIM}}$ rates the size of cutter used to generate the PFs and is based on the following assumptions:

○ The chosen cutting tool can be employed on the MMT on which MAS is implemented.

o The minimum radius of curvature of PFs' is larger than the diameter of the cutter; this is to allow the generation of the smallest milled features.

Figure 6 (a) shows the variation interval of $\mathrm{MI}_{\mathrm{DIM}}$ based on the cutting tool diameters.

2. Tolerance Index $\left(\mathrm{MI}_{\mathrm{TOL}}\right)$

This index is adapted from the International Tolerance Grades (ITG) based on the tolerance grade/class of precision (Rothbart 1985; Drake 1999). Figure 6(b) shows the range of $\mathrm{MI}_{\mathrm{TOL}}$ adapted from ITG with assumptions that micro-machining result fine tolerance grade (e.g. 2-4). However, the methodology of determining the index can accept other relevant tolerance values.

3. Surface Roughness Index $\left(\mathrm{MI}_{\mathrm{Ra}}\right)$

This index rates the difficulty of obtaining a minimum workpiece surface roughness as specified by the user when employing micro-machining (micro-milling/drilling) in the specified conditions (part geometry, workpiece material). A nominal value of $\mathrm{Ra}=0.5 \mu \mathrm{m}$ (Hoyle 2006) has been considered as a typical level of surface finish that can achieved when generating micro-features, Figure 6 (c) shows the rating of $\mathrm{MI}_{\mathrm{Ra}}$.

Figure 6. Index ratings for $\mathrm{MI}_{\mathrm{DIM}}, \mathrm{MI}_{\mathrm{TOL}}$ and $\mathrm{MI}_{\mathrm{Ra}}$

Table 5 shows the summarised MIs for each PF which are used to calculate (Equation 1) MISFA.

Table 5. Summary of $\mathrm{MI}_{\mathrm{SFA}}$ results

The results of $\mathrm{MI}_{\mathrm{CFA}}$ (Table 6) are based on the conditions stated in Table 2 and taking into consideration the relative distances between PFs shown in Figure 7. As example, PF_F is adjacent to PF_E with the $\mathrm{RD}=0.17 \mathrm{~mm}$ and based on the condition in Table 2, the initial value of $\mathrm{MI}_{\mathrm{SFA}}(0.7)$ is recalculated to 0.5 $\left(\mathrm{MI}_{\mathrm{SFA}} \mathrm{x} 0.75\right)$; the pre-defined ARD in this example is $0.1<\mathrm{ARD}<0.8 \mathrm{~mm}$.

Table 6. $\mathrm{MI}_{\mathrm{CFA}}$ results 
Figure 7. Examples of relative distances between PFs

Table 7 shows the overall result of MAS for the considered examples indicating a medium level of manufacturability since $\mathrm{MI}_{\mathrm{OVERALL}}$ is $\mathbf{0 . 8 4}$.

Table 7. $\mathrm{MI}_{\mathrm{OVERALL}}$ results

\subsection{Output generated}

In order to upgrade the manufacturability level of the proposed design, redesign suggestions are provided to user as follows:

- Modify the dimensions of the identified PFs that result in lower $\mathrm{MI}_{\mathrm{SFA}}$ values.

- Redefine the distances between PFs within the acceptable range.

- Modify the features that lowered the manufacturability index.

- Change the selected material to one which has a higher value of $\mathrm{MI}_{\mathrm{MAT}}$.

- Redefine the importance of the weight factors of $\mathrm{MI}_{\mathrm{SFA}}$ (Equation 1).

\section{Implementation of PFA}

\subsection{System development}

In order to visualise the implementation of PFA in MAS, a system developed in Visual Basic.NET® (VB) is demonstrated in the next paragraphs. The system named MicroMAS is built on a Rule-Based System (RBS), to assist decision making, and relies on a micro-milling/drilling database while being supported by VB for system interfaces and linkages (Figure 8). The stages of PFA in MAS (Table 8) are expanded to four main sequential stages: i) Initial Assessment (IA); ii) Single Feature Analysis (SFA); iii) Coupled Feature Analysis (CFA); iv) Output generated.

Figure 8. Relationships in MicroMAS

Table 8. Summary of PFA technique for MicroMAS

1. RBS and IF-THEN clauses

RBS through IF-THEN clauses controls the analysis of MicroMAS and represents the system knowledge base via logical combinations. RBS has been applied in manufacturing based inference engines because the IF-THEN rules are similar to common sense logic (Kusiak 1988). Furthermore, the concept of RBS and IF-THEN clauses can be implemented in any programming language or software packages including VB. In this paper, the related rules and conditions related to micro-milling/drilling and all PFs elements are saved in the form of IF-THEN clauses. All the rules and conditions stored in the database are interactively searched based on IF-THEN clauses in order to determine which rules satisfy the inputs.

2. Database

Related manufacturing information and rules are embedded in the database to be used as a guide for assessing the manufacturability of the proposed design. The database is the medium where all the data and 
information needed for the analysis are stored and was developed using Microsoft Access® and linked to VB.

3. Visual Basic.NET®

VB provides a user-friendly environment for developing interfaces and linkages that suits the PFA and the overall MicroMAS approach. The developed interfaces prompt the user with question leading towards the collection of information necessary to perform manufacturability analysis. Output reporting and pop-up forms (related feedbacks) have also been employed

\subsection{MicroMAS implementation}

\subsubsection{Input and Single Feature Analysis (SFA) interfaces}

Figure 9 shows the main interface where the input from the user is collected. As a guideline for entering and using this interface, the button "TO DO" is selected; a pop-up showing the guidance to fill in the form and assesses the preliminary result of the input is also presented in pop-up (a), Figure 9.

Figure 9. Main interface of MicroMAS

Fundamentally there are five important steps involved in the input mechanism as pictured in the Figure 9.

Step 1

The user uniquely labels the component, then identifies the number of PFs contained in the proposed design/component and selects the suitable workpiece material. At the moment, the list of materials available for user selections are only Steels, Titanium/ Copper/ Aluminium alloys. Efforts to populate relevant information for other workpiece materials are being made.

Steps 2 to 5 are repeated until details of all PFs have been input into the system and the result of $\mathrm{MI}_{\mathrm{SFA}}$ of each PF can be review in Step 5.

Step 2

For each identified PF, the user uniquely labels the PFs. Here, the data needed are based on the type, orientation, shape, and side angle of PF. This step reflects the required data for SFA Phase 2 discussed above.

Step 3

Geometrical data of each identified PF are required. The data depends on the type of PFs identified in Step 2 as each PF requires different geometrical data. In order to help the user input the relevant data according to the type of PF only the necessary geometrical characteristics are suggested by the system.

Step 4

Manufacturing related details such as process involved (micro-milling/drilling), diameter of the tools and part quality control measures (tolerance and surface finish) are required at this step for each PF. 
Step 5

This provides the generated result of $\mathrm{MI}_{\mathrm{Ra}}, \mathrm{MI}_{\mathrm{TOL}}$ and $\mathrm{MI}_{\mathrm{DIM}}$ and Stiffness ratios $\left(\mathrm{R}_{\mathrm{St}}\right)$. The $\mathrm{MI}_{\mathrm{Ra}}$, $\mathrm{MI}_{\mathrm{TOL}}$ and $\mathrm{MI}_{\mathrm{DIM}}$ are determined based on the related data input in Step 4 and the indices scheme described in Figure 6. A pop-up provides the result of $\mathrm{R}_{\mathrm{St}}$ value and determines whether it is within the preset acceptable ranges. Besides that, the result of $\mathrm{MI}_{\mathrm{PF}}$ is also assigned here based on the analysis discussed in Phase 2, while the calculated $\mathrm{MI}_{\mathrm{SFA}}$ for each PF is also provided in this form subjected to Equation 1.

Pop-up (b) in Figure 9 shows the highlighted warning which is imposed by the system if any of the input is out of the determined acceptable range stored in the database.

\subsubsection{Coupled Feature Analysis(CFA) interface}

Once the data input form reached the maximum number of PFs contained in the component, a CFA button appears on this interface (Figure 9) confirming the completion of this stage. A new interface referring to CFA phase appears (Figure 10), where the user has to input the relative distances (RDs) and the type of interactions between PFs. Based on RDs, the $\mathrm{MI}_{\mathrm{CFA}}$ for each PF is calculated as discussed in Phase 3. Figure 11 shows the result of $\mathrm{MI}_{\mathrm{CFA}}$ for each $\mathrm{PF}$.

Figure 10. Interface form for CFA

Figure 11. Overall result of MicroMAS

\subsubsection{Output}

The overall output of MicroMAS is shown in Figure 11 containing: $\mathrm{MI}_{\mathrm{SFA}}$ and $\mathrm{MI}_{\mathrm{CFA}}$ for each PF and MI OverAll of the analysed part. If a higher value of MIOVERALL is needed, then the system gives suggestions about changing manufacturability aspects of the part/PFs, e.g. dimensions, surface roughness, tolerances, workpiece material of PFs/part.

\section{CONCLUSION}

From the discussion made above, it shows that MicroMAS is capable to: i) executing the PFA technique in data input mechanism and manufacturability assessment; ii) defining the micro-part design based on PFs contained in it; iii) analysing the manufacturability aspects of the micro-part. Moreover, the calculated MI is also able to indicate the level of manufacturability for each PF (e.g. $\mathrm{MI}_{\mathrm{PF}}, \mathrm{MI}_{\mathrm{SFA}}, \mathrm{MI}_{\mathrm{CFA}}$ ) and its overall component $\left(\mathrm{MI}_{\mathrm{OVERALL}}\right)$. The conclusions from the development of MicroMAS can be summarized as follows:

- The backbone for the Primitive Feature Analysis (PFA) technique is the Primitive Feature (PF) concept which is combined with the positive (bosses) and negative (pockets) convention to define the component in details and produced meaningful interpretations.

- The PFA technique consists of two crucial phases which are SFA and CFA in defining the micro-parts and analysing its manufacturability. SFA was used for collecting essential data from the CAD model that are further "enriched" with part quality measures, proved to be efficient in providing "necessary and sufficient" input data to MicroMAS. Furthermore, SFA provides an efficient way (MI $\left.\mathrm{SFA}_{\mathrm{SF}}\right)$ to evaluate the manufacturability of each PF of the analysed part. Since the analysed part has many PFs, 
MicroMAS provides a systematic way to check interactions between them and to assess the manufacturability $\left(\mathrm{MI}_{\mathrm{CFA}}\right)$ of coupled features. This enables the manufacturability analysis of the part as a result of multi-feature interactions and not as an outcome of a single entity (rigid) assessment commonly used in the most reported work.

- A new sequential MI scheme is introduced to indicate the level of manufacturability for each PF and also for the overall micro-part. Based on the generated indices convention, the level of manufacturability for each PF (Equation 1) is determined based on several aspects such as PF (e.g. orientation, shape, type); dimensional tolerance; surface roughness; tools diameter and selected workpiece material. $\mathrm{MI}_{\text {OVERALL }}$ which indicates the overall manufacturability (Equation 3 ) of the component is calculated based on the aspects analysed above and also the interactions occurred between PFs. Besides the MI scheme provided to user, the system feedback takes the form of: suggestions to change manufacturability aspects of the part/PFs, e.g. dimensions, surface roughness, tolerances, workpiece material of PFs/part.

- Rule-Based System (RBS) approach proved an efficient method in determining the output measures on the assessments of the manufacturability aspects based on the IF-THEN clauses.

Even though, the execution of the PFA technique in MicroMAS is gradually reaching its maturity, the system is able to provide support by taking into consideration and analyse manufacturing aspects at the early stage of product development life cycles.

\section{Advantages and limitation}

The implementation of the PFA technique in MicroMAS has its own advantages and limitations. The main advantages of MicroMAS are listed below:

- Due to the overall PF approach and innovative methods of combining data input mechanisms, MicroMAS offers high flexibility for a user to get essential data from the analysed design. Furthermore, the user has full control in defining the analysed design in such a way that is independent of CAD systems.

- MicroMAS takes into consideration some quality measures (e.g. tolerance, roughness) that can affect the functionality of the analysed micro-part. Most of the current MAS focus solely in analysing manufacturability aspects while neglecting other important aspects such as part functionality (Shukor 2007).

- The level of manufacturability of the analysed micro-part is presented via a set of comprehensive and sequential aggregate indices (MIs) which provide clear and meaningful results for the user. This enables the breakdown of the overall manufacturability index into its sub-components to allow the identification of changes needed in the design and/or the specifications of part quality measures; this will permit efficient manufacture of the analysed part.

- MicroMAS is developed using VB which provides a robust and dynamic window-based application where any changes in the programming code can easily be done. MicroMAS also offers an openenvironment system that is dynamic and adaptable to any changes in the future.

- The implementation of RBS and IF-THEN clauses in assessing manufacturability provides a thorough analysis through all the determined rules and conditions.

Although MicroMAS has achieved its objectives, it still has its limitations as highlighted below:

- Even though it offers flexibility in defining the proposed design, the process depends on user "translation" of the design and thus some level of fuzziness might be introduced at the input stage. 
However, this gives option for user to decide the most suitable way to machine the proposed design on the MMT as various MIs results can be generated due to different interpretation of the design.

- The assessment is based on information structured in database that needs to be updated from time to time. However this is a common limitation for all developed systems.

- MicroMAS offers manufacturability assessment based only on two micro-machining processes (micromilling/drilling). However, as the MicroMAS is an open system, other micro-manufacturing processes can implement the foundation of this system development to fabricate its own MAS.

- The outputs produced in MicroMAS are limited only to aggregate indices (MI) and redesign suggestions. However, the MicroMAS framework provides an easy-approach in further adding more relevant outputs.

\section{Prospective future work and challenges}

It can be concluded that even though MicroMAS capable of analysing manufacturability aspects based on the PFA technique, there are still a wide area of improvements to be tackled. Based on critical analysis towards MicroMAS, the following areas of interest are identified for further research:

- MicroMAS is proposed to produce more combinations of outputs which it is believed will increase its effectiveness such as estimations of production cost and time as well as process sequencing.

- It is suggested to implement the PFA technique for developing MAS for other micro-manufacturing processes.

- For its data input mechanism, it is interesting to explore the development of an automatic data extraction tool from CAD model based on PFA technique. This approach can be combined with other input mechanisms for data verification.

- It is proposed to upgrade the functionality of MicroMAS by: providing an automated change scheme directly in the CAD model based on the redesign suggestion; generating an interactive guideline to assist user in operating the system easily.

- It is recommended to consider other manufacturing-related aspects such as ease of fixture and process capability.

\section{Acknowledgements}

The authors are grateful for the support from University of Nottingham where the research is carried out. Special thanks to Universiti Kebangsaan Malaysia for providing the main author's scholarship. 


\section{APPENDIX \\ Notation}

\begin{tabular}{|c|c|}
\hline MAS & Manufacturability Analysis System \\
\hline MMT & Miniature 4-Axis Machine Tool \\
\hline PFA & Primitive Feature Analysis \\
\hline MI & Manufacturability Index \\
\hline SFA & Single Feature Analysis \\
\hline CFA & Coupled Feature Analysis \\
\hline DFM & Design for Manufacturing \\
\hline $\mathrm{CE}$ & Concurrent Engineering \\
\hline $\mathrm{CAD}$ & Computer Aided Design \\
\hline CAM & Computer Aided Manufacturing \\
\hline IA & Initial Assessment \\
\hline RBS & Rule-Based System \\
\hline VB & Visual Basic.NET® \\
\hline $\mathrm{PF}$ & Primitive Feature \\
\hline $\mathrm{MI}_{\mathrm{PF}}$ & Manufacturability Index for Primitive Feature \\
\hline $\mathrm{MI}_{\mathrm{Ra}}$ & Manufacturability Index for Surface Roughness \\
\hline $\mathrm{MI}_{\mathrm{TOL}}$ & Manufacturability Index for Tolerance \\
\hline $\mathrm{MI}_{\mathrm{DIM}}$ & Manufacturability Index for Dimension \\
\hline $\mathrm{MI}_{\mathrm{SFA}}$ & Manufacturability Index for Single Feature Analysis phase \\
\hline $\mathrm{MI}_{\mathrm{CFA}}$ & Manufacturability Index for Coupled Feature Analysis phase \\
\hline $\mathrm{MI}_{\text {OVERALL }}$ & Manufacturability Index for overall component \\
\hline $\mathrm{MI}_{\mathrm{MAT}}$ & Manufacturability Index for material \\
\hline $\mathrm{R}_{\mathrm{St}}$ & Stiffness ratio \\
\hline LH & Length-to-Height ratio \\
\hline $\mathrm{DH}$ & Diameter-to-Height ratio \\
\hline $\mathrm{RD}$ & Relative Distance \\
\hline ARD & Acceptable Relative Distance \\
\hline $\mathrm{L}$ & Length \\
\hline $\mathrm{W}$ & Width \\
\hline $\mathrm{H}$ & Height \\
\hline $\mathrm{D}$ & Diameter \\
\hline$\alpha$ & Extension angle of the cilindrical surface \\
\hline$\delta$ & Prism angle \\
\hline$\beta$ & Surface angle \\
\hline$\theta$ & Side angle \\
\hline
\end{tabular}




\section{REFERENCE}

Alberz, A., Marz, J., 2004. Restriction of Production Engineering on Microspecific Product Development. Microsystem Technologies, 10 (3), 205-210.

Alting, L., Kimura, F., Hansen, H.N., and Bissacco, G., 2003. Micro Engineering. Annals of CIRP 52, 2 635658.

Alting, L., Kimura, F., Hansen, H.N., and Bissacco, G., 2003. Micro Engineering. Annals of CIRP 52, 2 635658.

Anon, 2006. Machinability Comparison Chart - Technical Resources for Manufacturing Professionals [online]. Available from: http://www.carbidedepot.com/formulas-machinability.htm [Accessed 9 October, 2006].

Boothroyd, G., Dewhurst, P. and Knight, W., 1994. Product Design for Manufacture and Assembly. New York: Marcel Dekker Inc.

Bralla, J. G., 1986. Handbook of Product Design for Manufacturing. USA: Mc Graw Hill

Brissaud, D., Tichkiewitch, S. , 2000. Innovation and Manufacturability Analysis in an Integrated Design Context. Computers in Industry 43 (2), 111-121.

Chen, C. H., Occena, L.G., and Fok, S.C., 2001. CONDENSE:A Concurrent Design Evaluation System for Product Design. International Journal of Production Research, 39 (3), 413-433.

Cherian, R. P., Midha, P.S., Smith, L.N., and Pipe, A.G., 2001. Knowledge based and Adaptive Computational Techniques for Concurrent Design for Powder Metallurgy Parts. Advances in Engineering Software, 32 (6), 455-465.

Dimov, S., Pham, D.T., Ivano, A., Popov, K., and Fansen, K., 2004. Micromilling Strategies: Optimization Issues. Proceedings of the I MECH E Part B Journal of Engineering Manufacture, 218 (7), 731-736.

Drake, P. J., 1999. Dimensioning and Tolerancing Handbook. New York: Mc Graw Hill.

Gebresenbet, T., Jain, P.K., and Jain, S.C., 2002. Preliminary Manufacturability Analysis Using featurefunction - Resource Considerations for Cylindrical Machined Parts. International Journal of Computer Integrated Manufacturing, 15 (4), 361-378.

Giachetti, R. E., 2005. Integrating Hypermedia Design Concepts with A Systems Analysis and Design Methodology to Develop Manufacturing Web Applications. International Journal of Computer Integrated Manufacturing, 18 (4), 329-340.

Gupta, S. K., Regli, W.C., Das, D. and Nau, S., 1997. Automated Manufacturability Analysis: A Survey. Research in Engineering Design, 9 (3), 168-190.

Hoyle, R., 2006. Microelectrodischarge Machining - How to machine microfeatures and parts of a few microns in size in many different materials. [online]. Available from: http://www.devicelink.com/mdt/archive/06/05/006.html [Accessed 10 October, 2006].

Jacquel, D., Salmon, J., 2000. Design for Manufacturability: A Feature-Based Agent-Driven Approach. Proceedings of the Institution of Mechanical Engineers, Part B: Journal of Engineering Manufacture, 214 (10), 865-879.

Jia, H. Z., Ong, S.K., Fuh, J.Y.H., Zhang, Y.F., and Nee, A.Y.C. , 2004. An Adaptive and Upgradeable Agent-based System for Coordinated Product Development and Manufacture. Robotics and ComputerIntegrated Manufacturing 20 (2), 79-90.

Kamrani, A. K., 1996. An Integrated Knowledge-based System for Product Design Feasibility and Manufacturability Analysis. Computers Industrial Engineering, 31 (1-2), 83-86.

Korosec, M., Balic, J. and Kopac, J., 2005. Neural Network based Manufacturability Evaluation of Free Form Machining. International Journal of Machine Tools and Manufacture, 45 (1), 13-20. 
Kumar, S., Singh, R. and Sekhon G.S., 2006. CCKBS: A Component Check Knowledge-based System for Assessing Manufacturability of Sheet Metal Parts. Journal of Material Processing Technology, 172 (1), 64-69.

Kusiak, A., Chen, M., 1988. Expert Systems for Planning and Scheduling Manufacturing Systems. European Journal of Operational Research, 34 (2), 113-130.

Lee, R. S., Chen, Y.M. and Lee, C.Z., 1997. Development of a Concurrent Mold Design System: A Knowledge-based Approach. Computer Integrated Manufacturing Systems, 10 (4), 287-307.

Masuzawa, T., 2000. State of the art of micromachining. CIRP Annals - Manufacturing Engineering, 49 (2), 473-488.

Nasr, E. A., Kamrani, A.K., 2007. Computer-Based Design and Manufacturing: An Information-based Approach. New York, USA: Springer Science+Business Media, LLC.

Ong, S. K., Chew, L.C., 2000. Evaluating the Manufacturability of Machined Parts and Their Setup Plans International Journal of Production Research, 38 (11), 2397-2415.

Ong, S. K., Nee, A.Y.C., 1996. An Intelligent Fuzzy Set-up Planner for Manufacturability and Fixturability Evaluations. International Journal of Production Research, 34 (3), 665-686.

Ong, S. K., Sun, M.J. and Nee, A.Y.C., 2003. A Fuzzy Set AHP-based DFM Tool for Rotational Parts. Journal of Material Processing Technology, 138 (1-3), 223-230.

Pham, D. T., Dimov, S.S., 1998. An Approach to Concurrent Engineering. Proceeding of Institutional of Mechanical Engineers, 212 (B), 13 - 27.

Ramana, K. V., Singh, M., Gupta, A., Dey, R., Kapoor, A. and Rao, P.V.M., 2006. A Manufacturability Advisor for Spun and Roll formed Sheet Metal Components. International Journal of Advanced Manufacturing Technology, 28 (3-4), 249-254.

Rao, S. K., 1994. The Development of Fuzzy Cognitive Map for Manufacturability Analysis Based on Part Features. MS thesis. Texas A\&M University-Kingsville.

Rao, S. S., Nahm, A., Shi, Z., Deng, X. and Syamil, A., 1999. Artificial Intelligence and Expert System Applications in New Product Development - A Survey. Journal of Intelligent Manufacturing, 10 (3-4), 231-244.

Ravinwongse, R., 1997. An Intelligent Design Tool for Manufacturability Evaluation of Injection Molded Parts. Thesis (PhD). University of Missouri-Rolla.

Rothbart, H. A., 1985. Mechanical Design Handbook. New York: Mc Graw Hill

Sasaki, Y., Sonda, M., and Ito, K., 2003. Development of a Computer-aided Process Planning System Based on a Knowledge Base. Journal of Marine Science and Technology, 7 (4), 175-179.

Shukor, S. A., Axinte, D.A., 2007. Manufacturability analysis system: Issues and future trends. International Journal of Production Research, 1-22.

Smith, L. N., Midha P.S., 1999. A Knowledge Based System for Optimum and Concurrent Design, and Manufacture by Powder Metallurgy Technology. International Journal of Production Research, 37 (1), $125-137$.

Tomovic, M., 2006. Geometric Constraint Toolbox for Foundry Tooling, MS Powerpoint.

Venkatachalam, A. R., Mellichamp, J.M. and Miller D.M., 1993. A Knowledge-based Approach to design for Manufacturability. Journal of Intelligent Manufacturing, 4 (5), 355-366.

Yuyin, S., Bopeng, Z., Fuzhi, C. and Qingguo, M. , 1996. "A Knowledge-based Design for Manufacture System", IEEE International Conference on Systems, Man and Cybernetics 1996, Beijing, China, $1220-1224$.

Zha, X. F., Du, H., 2003. Manufacturing Process and Material Selection in Concurrent Collaborative Design of MEMS Devices. Journal of Micromechanics and Microengineering, 13 (5), 509-522. 


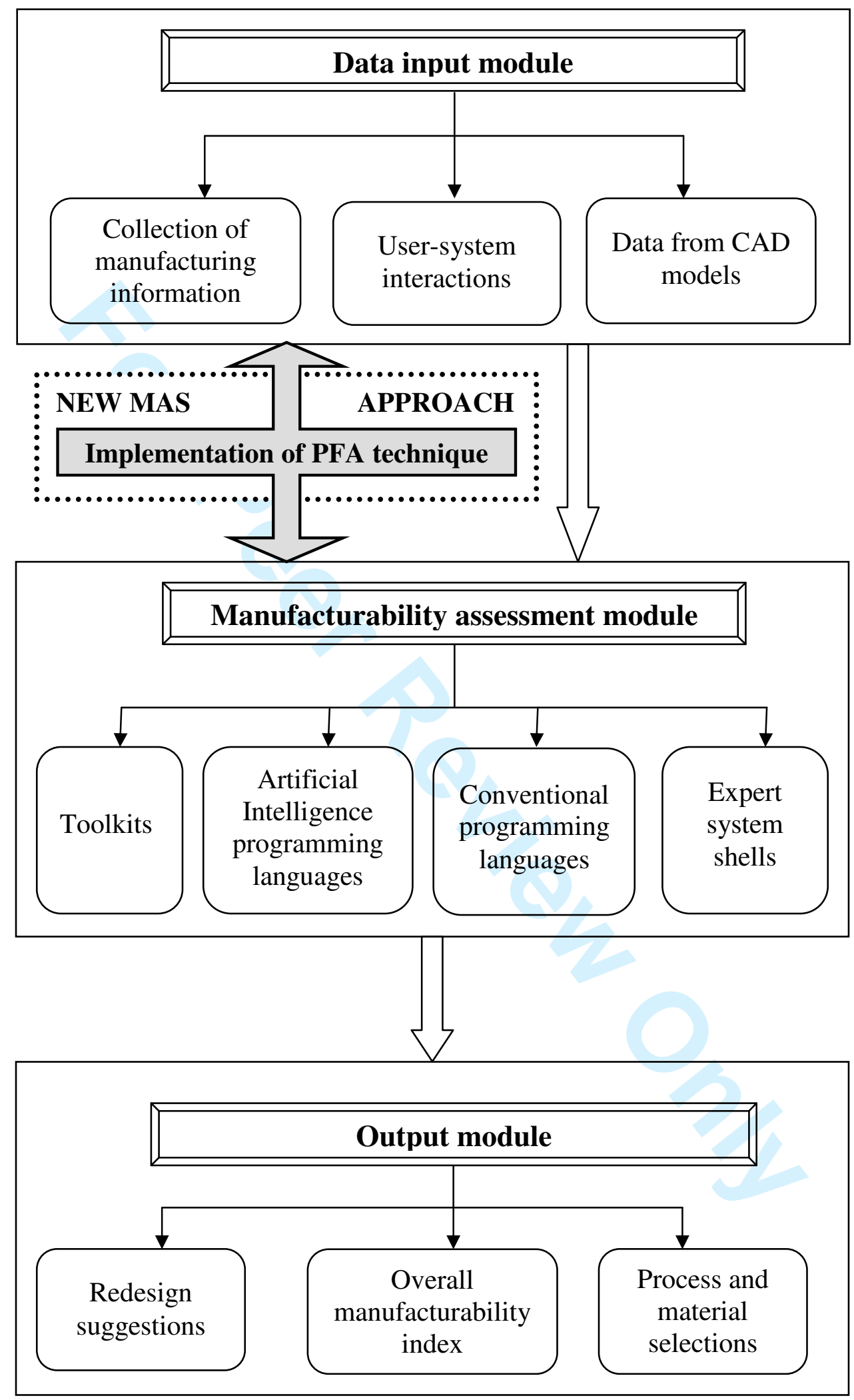

Figure 1. Basic methodology of MAS development 


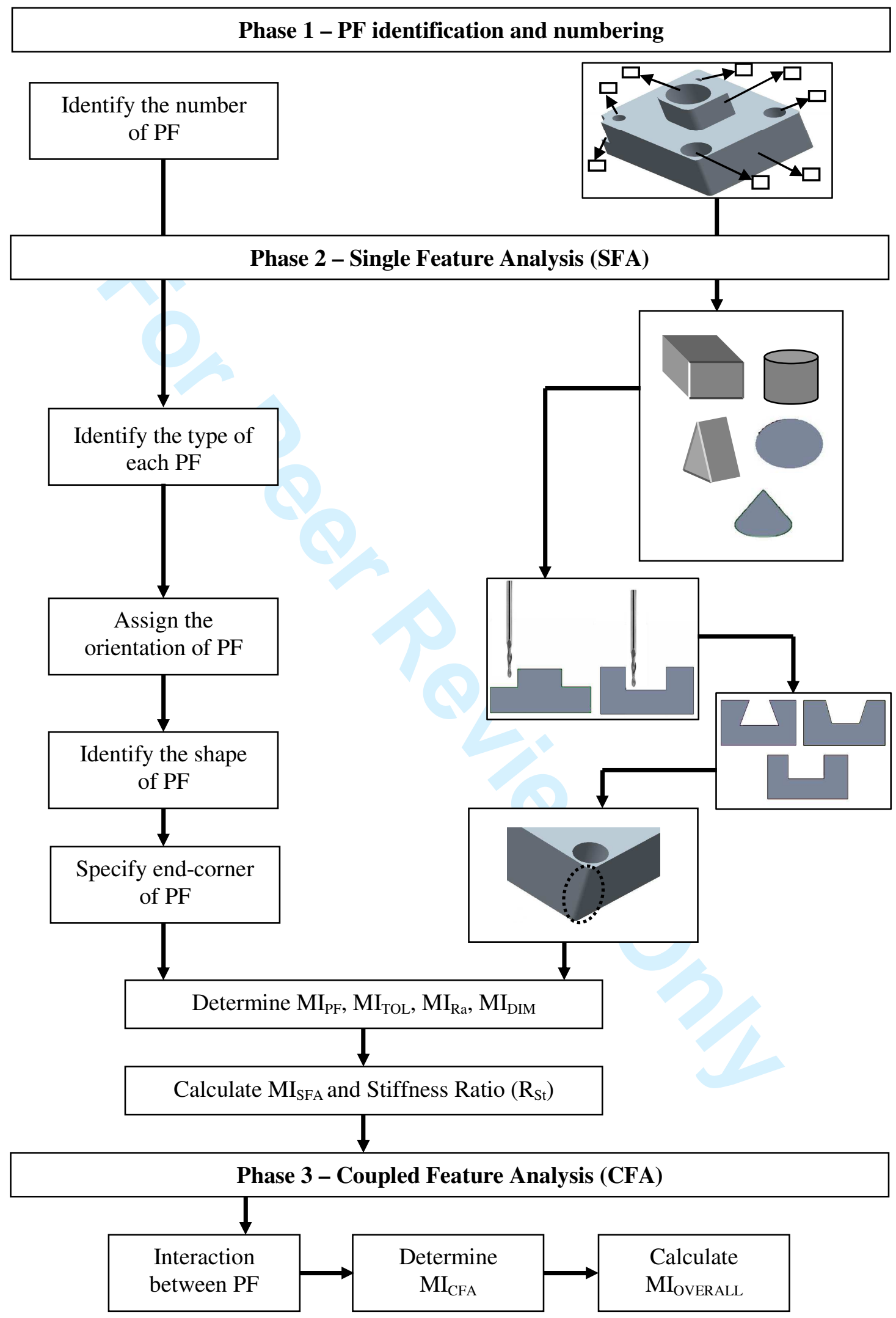

Figure 2. Flowchart and illustration of PFA technique 


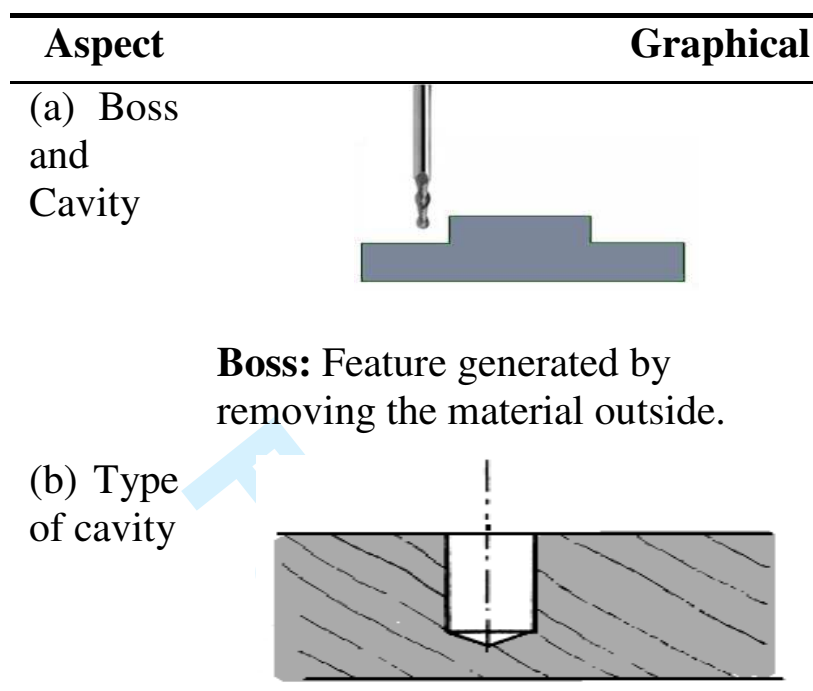

Type: Blind
Cavity: Feature that is generated by removing the material inside
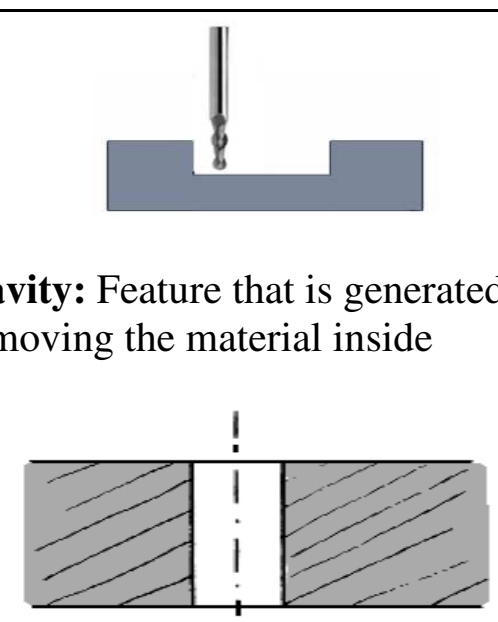

Type: Through

(c)

Side Angle
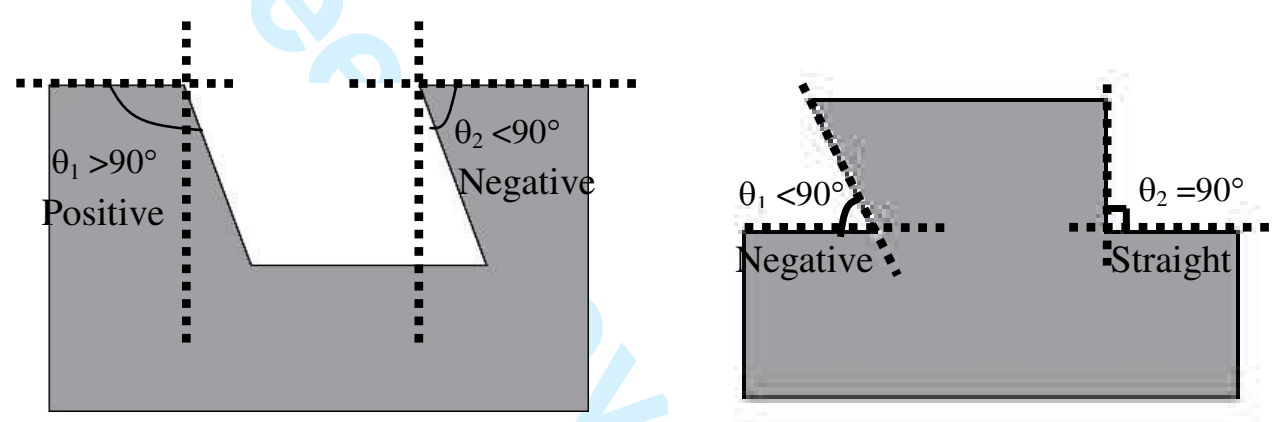

$\theta_{1}, \theta_{2}=$ side angle (defines the shape of the features)

d)

End-

corner

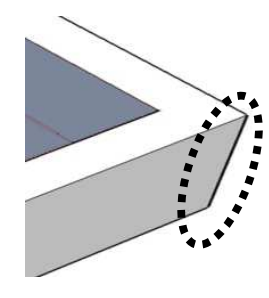

Sharp

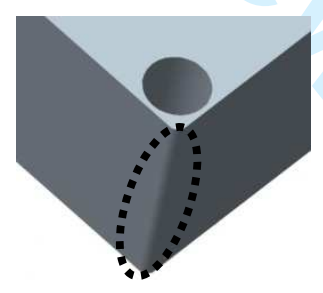

Radiused

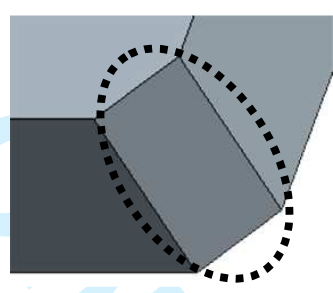

Fillet

(e)

Stiffness

Ratio

$\left(\mathrm{R}_{\mathrm{St}}\right)$
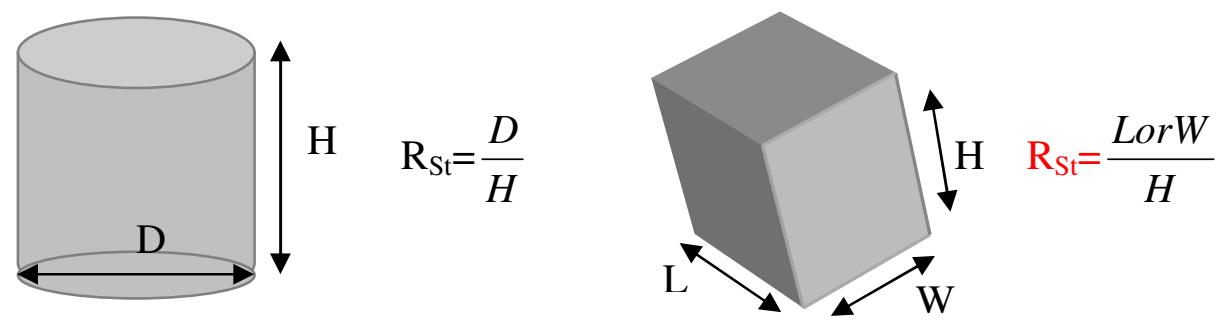

Figure 3. Single Feature Analysis terminology 


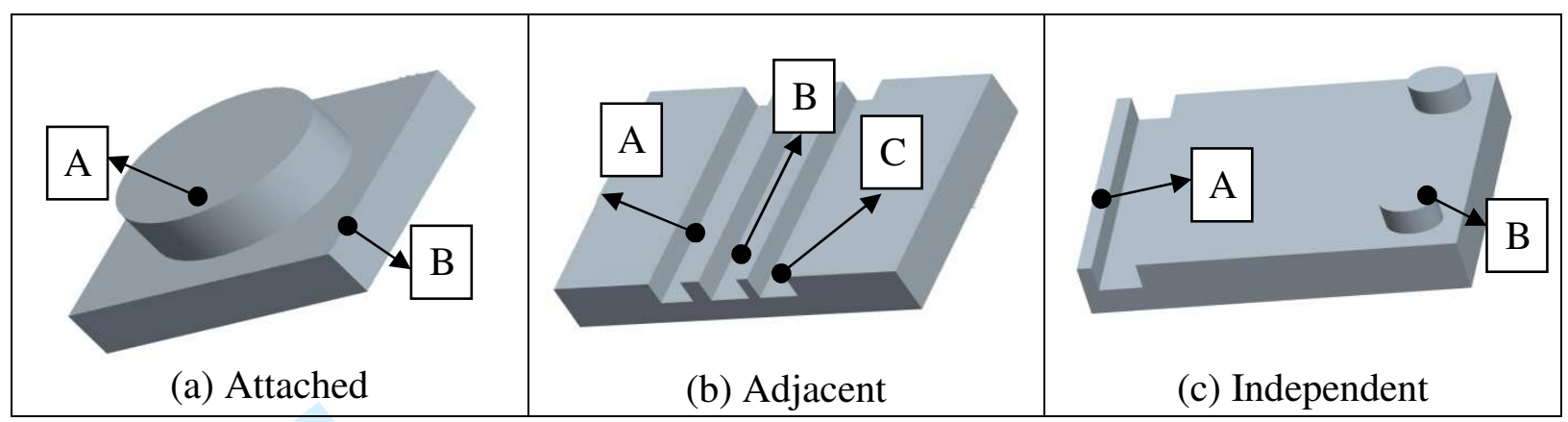

Figure 4. Types of PFs interactions

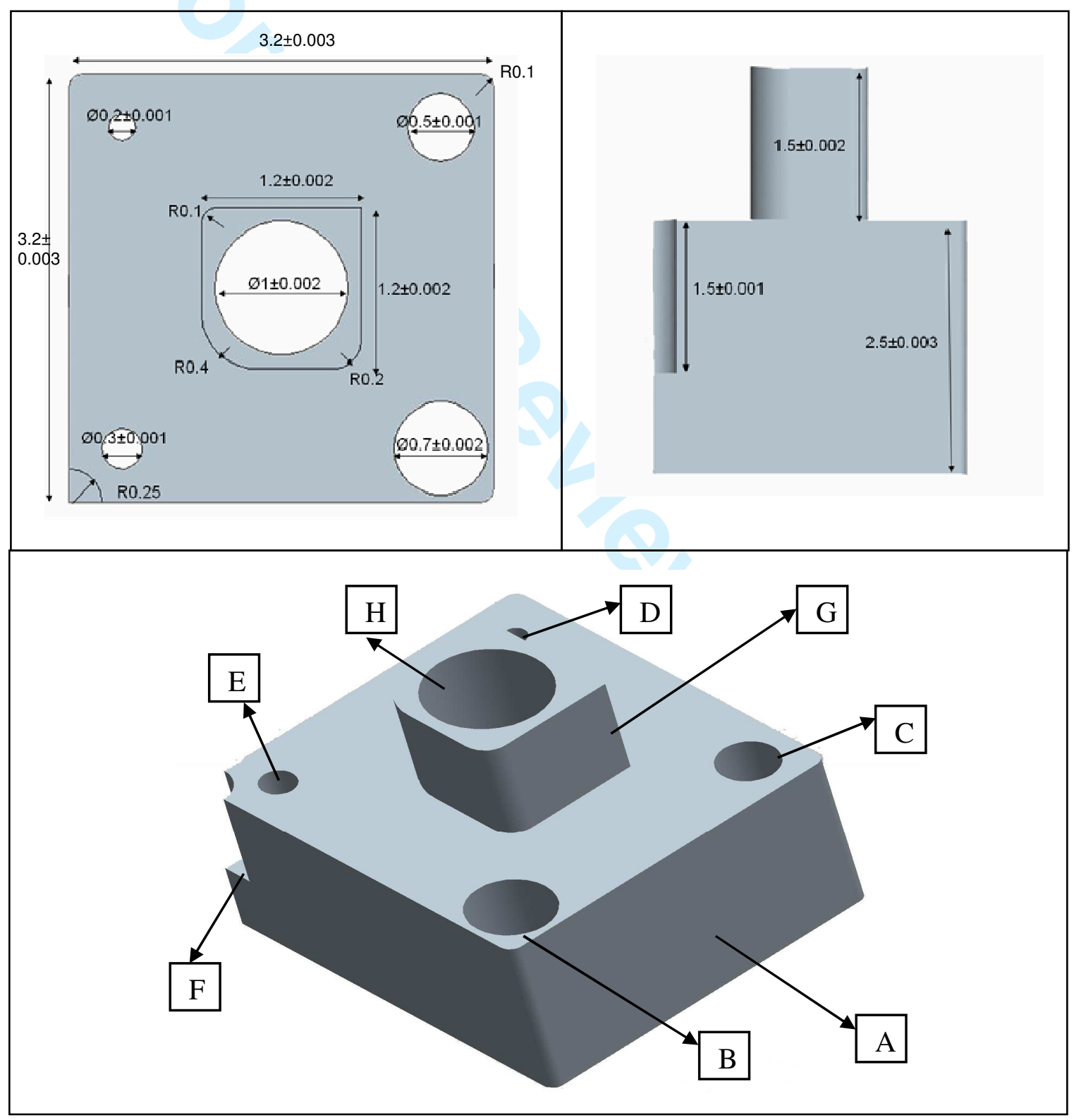

Figure 5. Views of the proposed design 


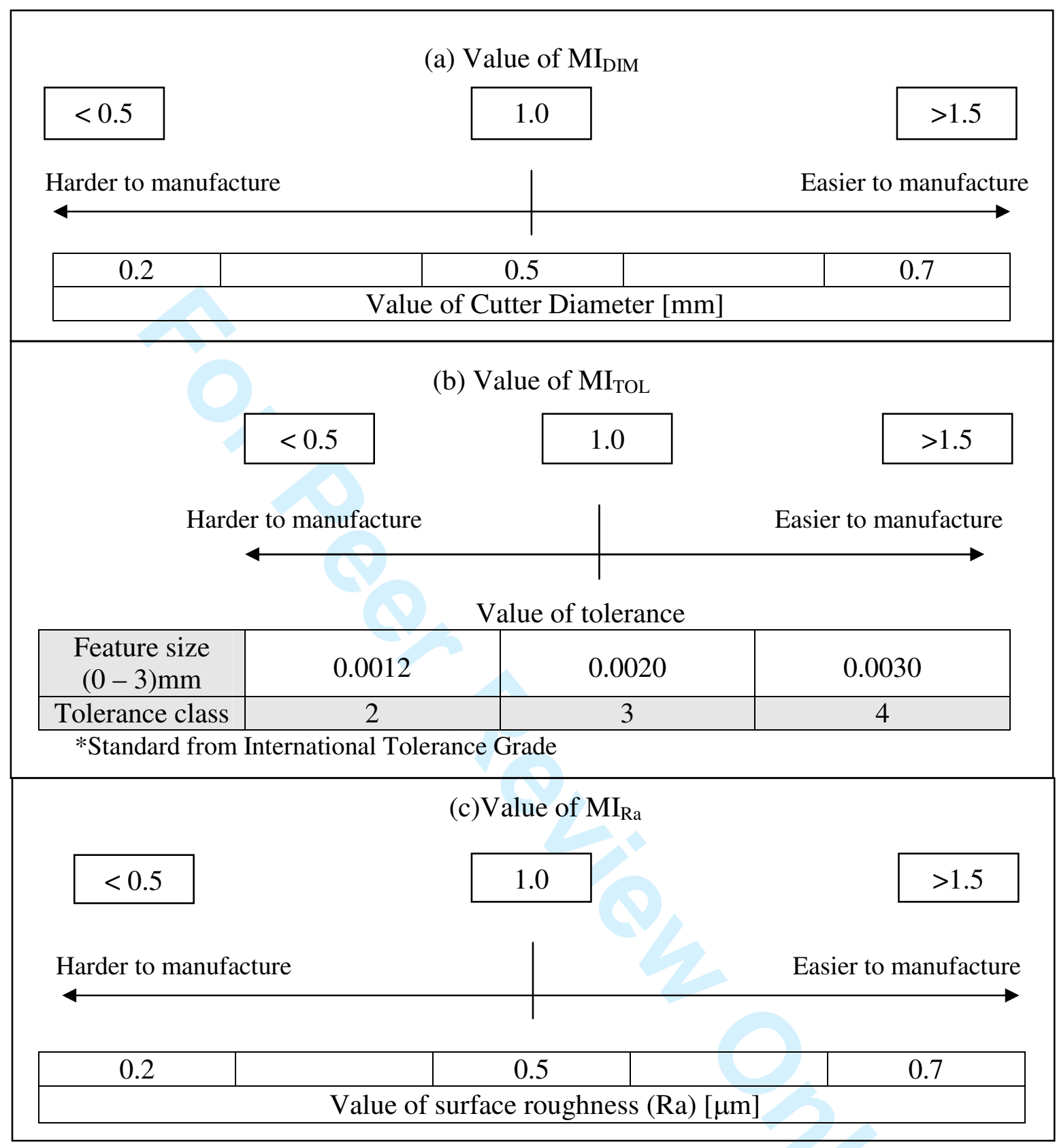

Figure 6. Index ratings for $\mathrm{MI}_{\mathrm{DIM}}, \mathrm{MI}_{\mathrm{TOL}}$ and $\mathrm{MI}_{\mathrm{Ra}}$ 


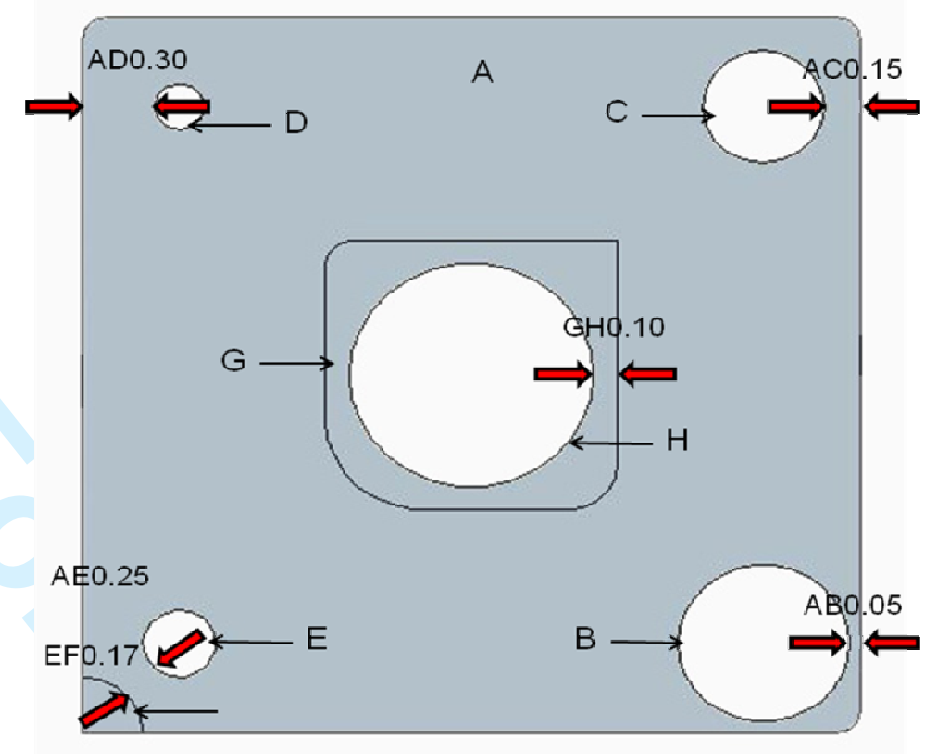

Figure 7. Examples of relative distances between PFs

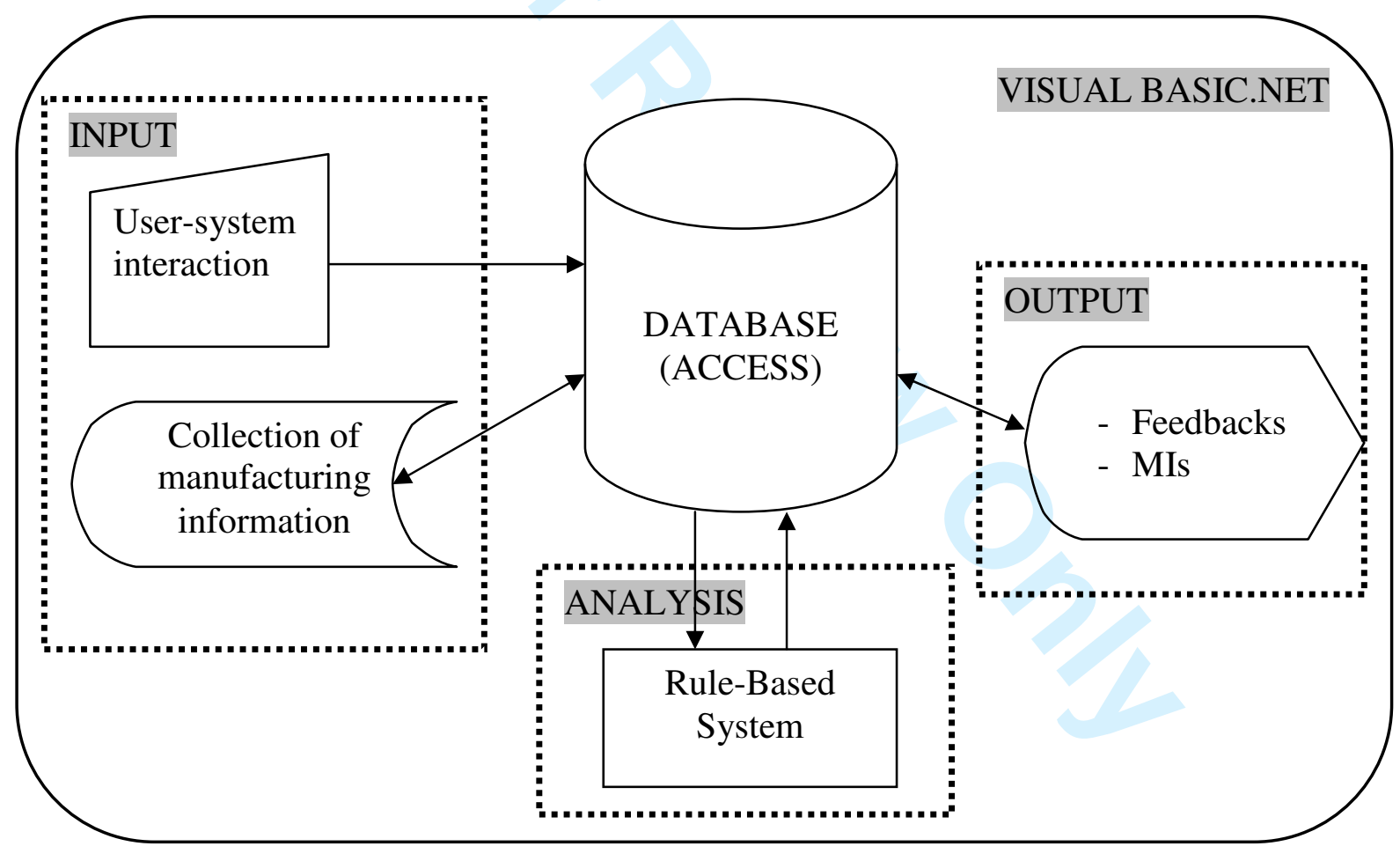

Figure 8. Relationships in MicroMAS 


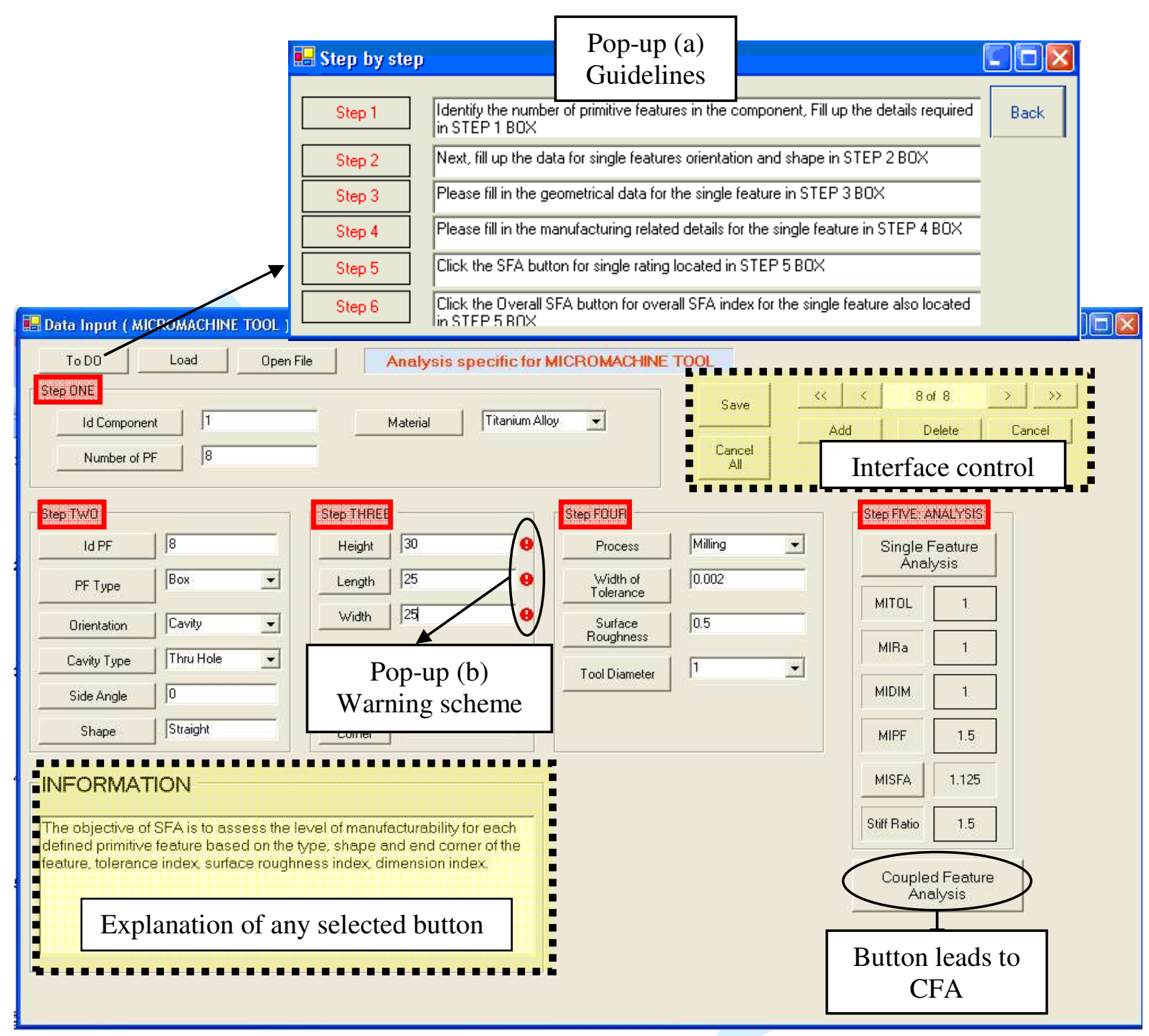

Figure 9. Main interface of MicroMAS 


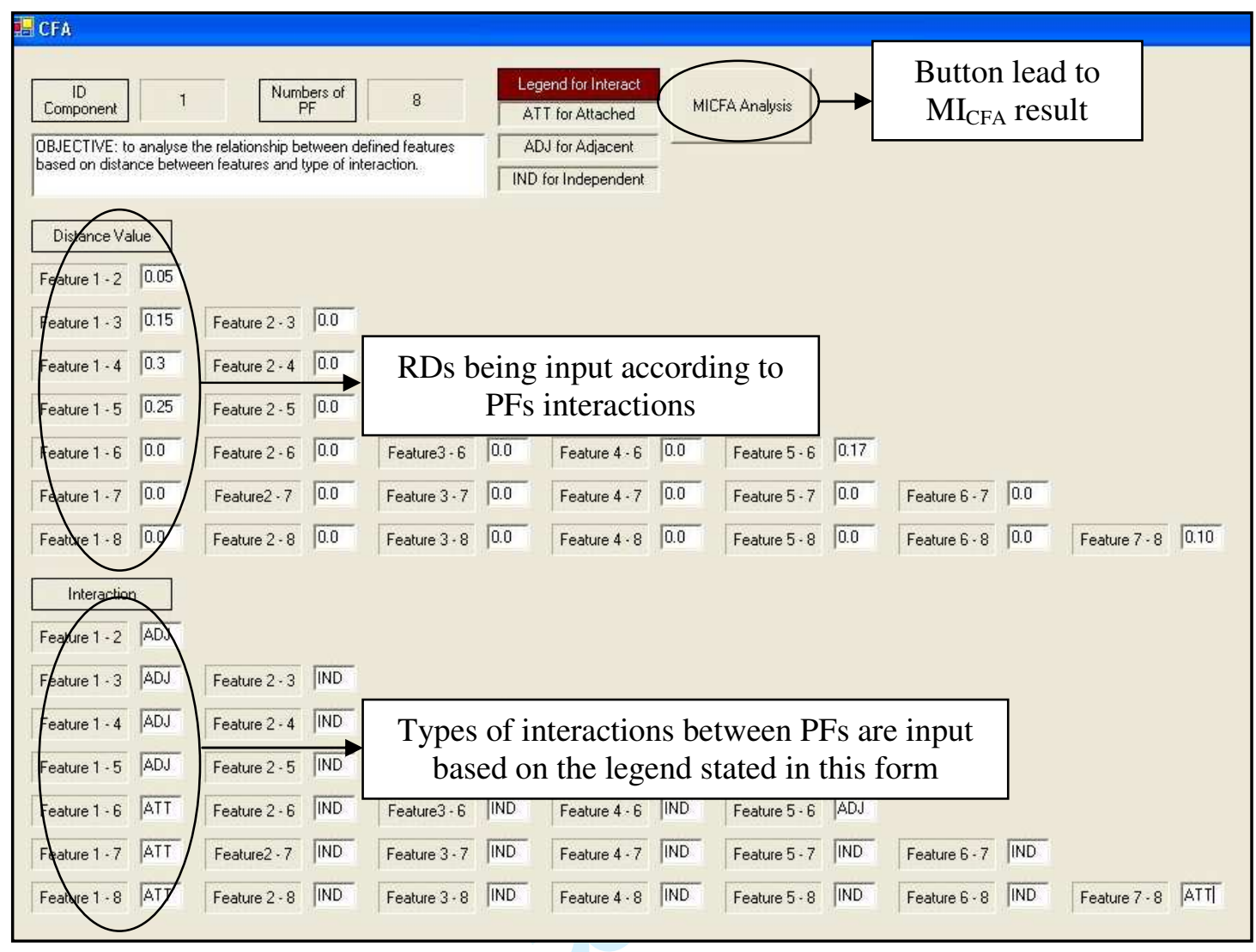

Figure 10. Interface form for CFA

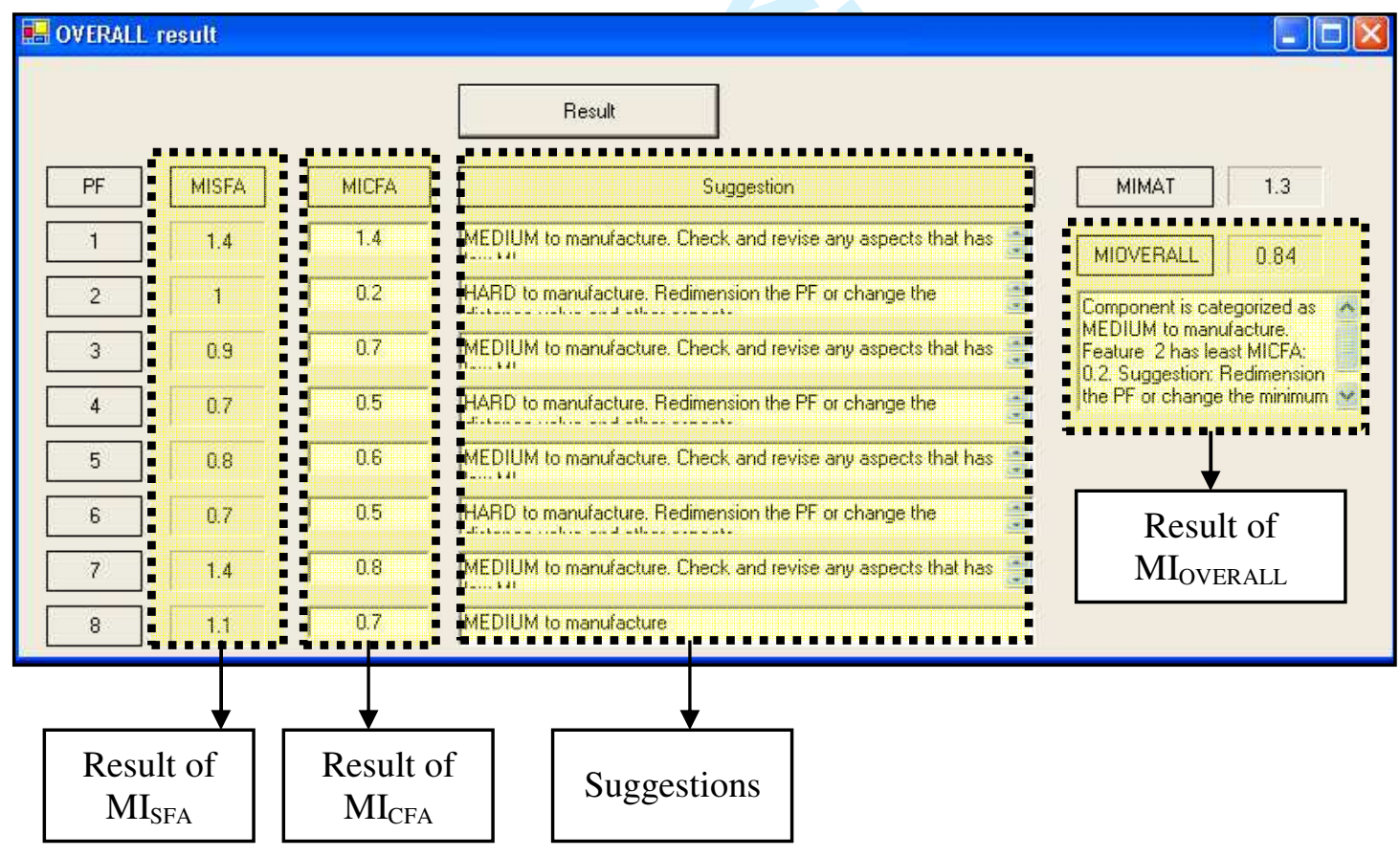

Figure 11. Overall results of MicroMAS 
Table 1. Illustration of Primitive Features

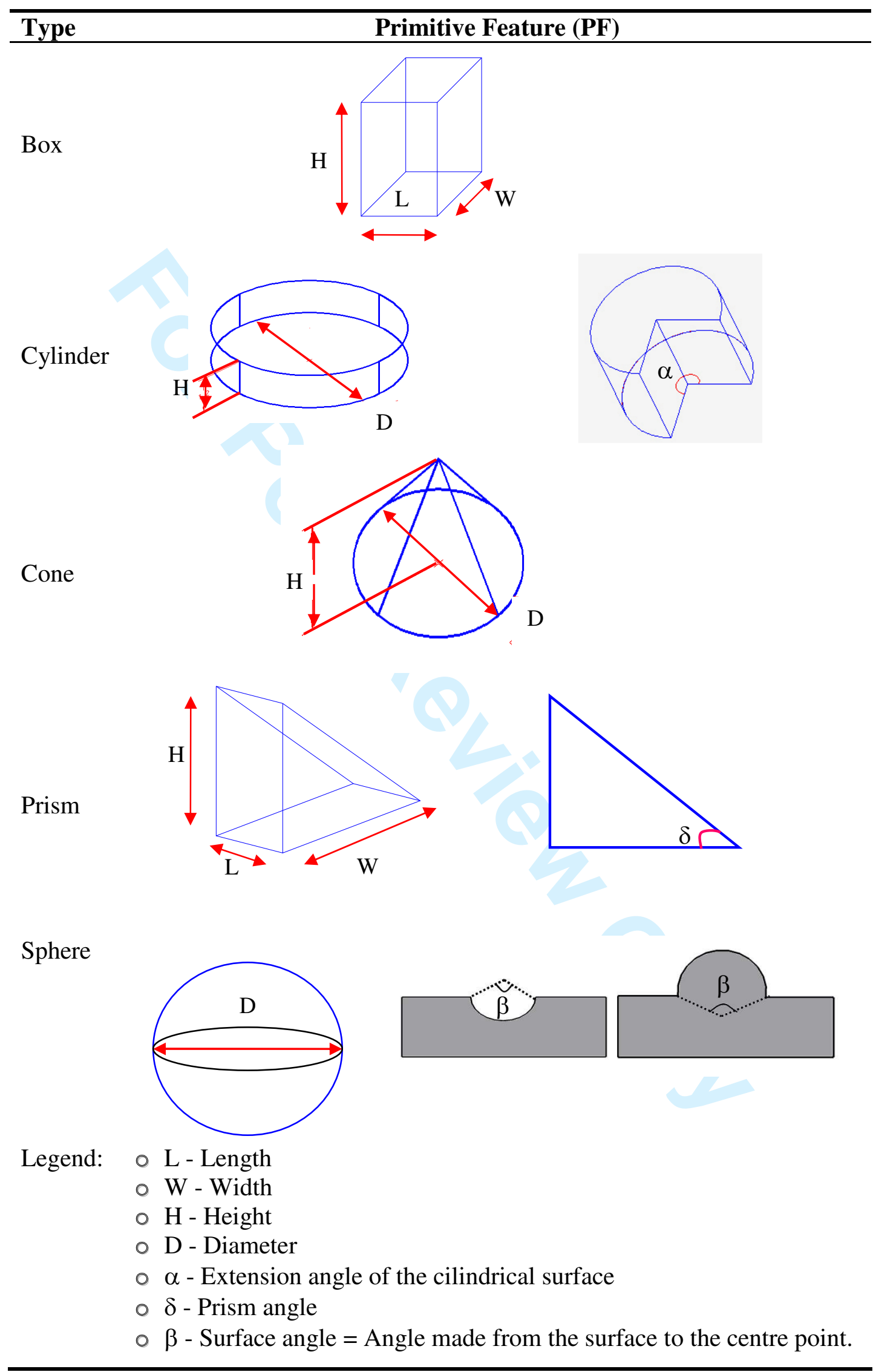


Table 2. Specification of $\mathrm{K}_{\mathrm{RD}}$ for calculating CFA index (MI $\left.\mathrm{IFA}_{\mathrm{C}}\right)$

\begin{tabular}{lcc}
\hline $\begin{array}{l}\text { Feature } \\
\text { Classification }\end{array}$ & Distance between PFs $(\mathbf{m m})$ & MI $_{\mathbf{C F A}}=\mathbf{M I}_{\text {SFA }} \times \mathbf{K}_{\mathbf{R D}}$ \\
\hline Attached & $\mathrm{RD}<\mathrm{ARD}$ & $\mathrm{MI}_{\text {SFA }} \times 0.30$ \\
& $\mathrm{RD}=\mathrm{ARD}$ & $\mathrm{MI}_{\text {SFA }} \times 0.40$ \\
& $\mathrm{RD}>\mathrm{ARD}$ & $\mathrm{MI}_{\mathrm{SFA}} \times 0.75$ \\
& $\mathrm{No} \mathrm{RD}$ & $\mathrm{MI}_{\text {SFA }} \times 1.00$ \\
Adjacent & $\mathrm{RD}<\mathrm{ARD}$ & $\mathrm{MI}_{\text {SFA }} \times 0.10$ \\
& $\mathrm{RD}=\mathrm{ARD}$ & $\mathrm{MI}_{\text {SFA }} \times 0.20$ \\
& $\mathrm{RD}>\mathrm{ARD}$ & $\mathrm{MI}_{\text {SFA }} \times 0.65$ \\
Independent & $\mathrm{RD} \leq \mathrm{ARD}$ & $\mathrm{MI}_{\text {SFA }} \times 1.00$ \\
& $\mathrm{RD}>\mathrm{ARD}$ & $\mathrm{MI}_{\text {SFA }} \times 1.00$ \\
\hline
\end{tabular}

Note: RD - Relative Distance

ARD - Acceptable Relative Distance

Table 3. Results from Single Feature Analysis

\begin{tabular}{cccccccc}
\hline PF & $\begin{array}{c}\text { Type of } \\
\text { PF }\end{array}$ & $\begin{array}{c}\text { PF } \\
\text { Orientation } \sum\end{array}$ & $\begin{array}{c}\text { Type of } \\
\text { Cavity }\end{array}$ & $\begin{array}{c}\text { PF } \\
\text { Shape }\end{array}$ & $\begin{array}{c}\text { End- } \\
\text { corner }\end{array}$ & MI $_{\mathbf{P F}}$ & $\begin{array}{c}\text { Stiffness } \\
\text { Ratio }\left(\mathbf{R}_{\text {St }}\right)\end{array}$ \\
\hline A & Box & Boss & N/A & Straight & Radiused & 1.5 & 2.1 \\
$\ldots$ & $\ldots$ & $\ldots$ & $\ldots$ & $\ldots$ & $\ldots$ & $\ldots$ & $\ldots$ \\
$\ldots$ & $\ldots$ & $\ldots$ & $\ldots$ & $\ldots$ & $\ldots$ & $\ldots$ & $\ldots$ \\
F & Cylinder & Cavity & Through hole & Straight & None & 1.0 & 0.2 \\
G & Box & Boss & N/A & Straight & Radiused & 1.5 & 0.8 \\
H & Cylinder & Cavity & Through hole & Straight & None & 1.5 & 0.7 \\
\hline
\end{tabular}

Note: N/A - not applicable

Table 4. An example of PF analysis: A box condition

\begin{tabular}{cccccc}
\hline $\begin{array}{c}\text { Type of } \\
\text { PF }\end{array}$ & $\begin{array}{c}\text { PF } \\
\text { orientation }\end{array}$ & $\begin{array}{c}\text { Type of } \\
\text { Cavity }\end{array}$ & $\begin{array}{c}\text { PF } \\
\text { Shape }\end{array}$ & $\begin{array}{c}\text { End- } \\
\text { corner }\end{array}$ & MI $_{\mathbf{P F}}$ \\
\hline Box & Boss & N/A & Straight & Radiused & 1.5 \\
& & N/A & Negative-tapered & Radiused & 0.5 \\
& N/A & Positive-tapered & Radiused & 1.0 \\
& Cavity & Through hole & Straight & Radiused & 1.5 \\
& & Blind & Straight & Radiused & 1.0 \\
& & Through hole & Negative-tapered & Radiused & 0.5 \\
& Blind & Negative-tapered & Radiused & 0.5 \\
& & Through hole & Positive-tapered & Radiused & 1.0 \\
& & Blind & Positive-tapered & Radiused & 1.0 \\
\hline
\end{tabular}

Note: N/A - not applicable 
Table 5. Summary of $\mathrm{MI}_{\mathrm{SFA}}$ results

\begin{tabular}{cccccc}
\hline $\mathbf{P F}$ & $\mathbf{M I}_{\mathbf{P F}}$ & $\mathbf{M I}_{\mathbf{T O L}}$ & $\mathbf{M I}_{\text {DIM }}$ & $\mathbf{M I}_{\mathbf{R a}}$ & $\mathbf{M I}_{\mathbf{S F A}}(\mathbf{E q}$. 2) \\
\hline $\mathrm{A}$ & 1.5 & 1.5 & 1.2 & 1.4 & 1.4 \\
$\ldots$ & $\ldots$ & $\ldots$ & $\ldots$ & $\ldots$ & $\ldots$ \\
$\ldots$ & $\ldots$ & $\ldots$ & $\ldots$ & $\ldots$ & $\ldots .7$ \\
$\mathrm{~F}$ & 1.0 & 1.0 & 0.4 & 0.8 & 1.4 \\
$\mathrm{G}$ & 1.5 & 1.5 & 1.2 & 1.4 & 1.1 \\
$\mathrm{H}$ & 1.5 & 1.0 & 1.0 & 1.0 & \\
\hline
\end{tabular}

Table 6. $\mathrm{MI}_{\mathrm{CFA}}$ results

\begin{tabular}{ccccc}
\hline $\mathbf{P F}$ & $\begin{array}{c}\text { Interactions } \\
\text { analysis }\end{array}$ & Distance $(\mathbf{m m})$ & $\mathbf{M I}_{\mathbf{S F A}}$ & MI $_{\text {CFA }}$ \\
\hline $\mathrm{A}$ & Attached & - & 1.4 & 1.4 \\
$\ldots$ & $\ldots$ & $\ldots$ & $\ldots$ & $\ldots$ \\
$\ldots$ & $\ldots$ & $\ldots$ & $\ldots$ & $\ldots$ \\
$\mathrm{F}$ & Adjacent & 0.17 & 0.7 & 0.5 \\
$\mathrm{G}$ & Attached & 0.1 & 1.4 & 0.8 \\
$\mathrm{H}$ & Attached & 0.1 & 1.1 & 0.7 \\
\hline
\end{tabular}

Table 7. $\mathrm{MI}_{\text {OVERALL }}$ results

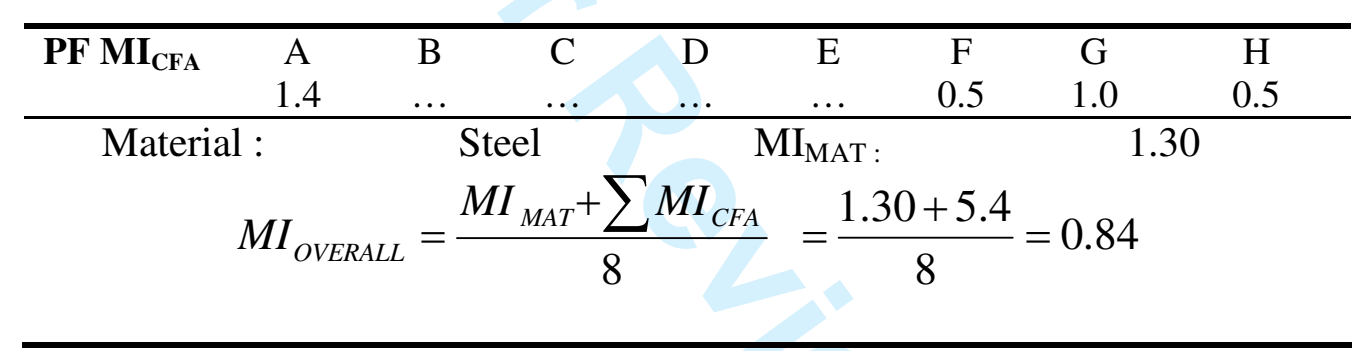


Table 8. Summary of PFA technique for MicroMAS

\begin{tabular}{|c|c|c|}
\hline Stage & Objective & Expected Output \\
\hline $\begin{array}{l}\text { Initial } \\
\text { Assessment }\end{array}$ & $\begin{array}{ll}\text { - } & \text { Identify numbers of PFs } \\
\text { - } & \text { Verify dimensions of the part/features }\end{array}$ & Error notification \\
\hline SFA & $\begin{array}{r}-\quad \text { Assess each PF } \\
\text { - } \quad \text { Verify stiffness ratio }\left(\mathrm{R}_{\mathrm{ST}}\right) \\
\text { - } \text { Calculate MISFA (Equation 1): } \\
M I_{S F A}=\frac{\sum K_{i} \cdot M I_{i}}{4}, \\
i=\mathrm{PF}, \mathrm{Ra}, \mathrm{TOL}, \mathrm{DIM}\end{array}$ & $\mathrm{MI}_{\mathrm{SFA}}$ \\
\hline CFA & $\begin{array}{l}\text { - Assess the relationships between the PFs } \\
\text { and calculate } \mathrm{MI}_{\mathrm{CFA}}\end{array}$ & $\mathrm{MI}_{\mathrm{CFA}}$ \\
\hline Output & $\begin{array}{c}\text { - } \quad \text { Calculate } \mathrm{MI}_{\text {OVERALL }}(\text { Equation 3): } \\
M I_{\text {OVERALL }}=\frac{M I_{M A T}+\sum_{n=1}^{n+1} M I_{C F A}}{n} \\
\mathrm{n}=\text { number of } \mathrm{PFs}\end{array}$ & $\begin{array}{l}\mathrm{MI}_{\text {OVERALL }} \\
\text { Overall redesign suggestions }\end{array}$ \\
\hline
\end{tabular}

